\title{
Um balanço da antropologia da saúde no Brasil e seus diálogos com as antropologias mundiais
}

Assessing the anthropology of health in Brazil and its dialogue with World

Anthropologies

\section{Esther Jean Langdon, Maj-Lis Follér e Sônia Weidner Maluf}

\section{(2) OpenEdition}

Edição electrónica

URL: http://journals.openedition.org/aa/254

DOI: $10.4000 /$ aa. 254

ISSN: 2357-738X

\section{Editora}

Programa de Pós-Graduação em Antropologia Social (UnB)

Edição impressa

Data de publição: 1 julho 2012

Paginação: 51-89

ISSN: 0102-4302

\section{Refêrencia eletrónica}

Esther Jean Langdon, Maj-Lis Follér e Sônia Weidner Maluf, «Um balanço da antropologia da saúde no Brasil e seus diálogos com as antropologias mundiais», Anuário Antropológico [Online], v.37 n. 1 | 2012, posto online no dia 01 outubro 2013, consultado o 28 abril 2021. URL: http://journals.openedition.org/ aa/254 ; DOI: https://doi.org/10.4000/aa.254

\section{(c) $(1)(9)$}

Anuário Antropológico is licensed under a Creative Commons Atribuição-Uso Não-Comercial-Proibição de realização de Obras Derivadas 4.0 International. 


\title{
Um balanço da antropologia da saúde no Brasil e seus diálogos com as antropologias mundiais
}

\author{
Esther Jean Langdon \\ Universidade Federal de Santa Catarina, Brasil \\ Maj-Lis Follér \\ University of Gothenburg, Suécia \\ Sônia Weidner Maluf \\ Universidade Federal de Santa Catarina, Brasil
}

O início da antropologia da saúde contemporânea no Brasil pode ser datado da década de 1970, quando um grupo interinstitucional de Brasília e o Museu Nacional realizaram uma pesquisa sobre as práticas alimentares em vários grupos subalternos no país. Desde este data, as pesquisas antropológicas em temas relacionados à saúde vêm crescendo e antropólogos têm participado de eventos organizados no campo de saúde coletiva e em simpósios e grupos de trabalho sobre o tema da saúde e em outros mais gerais da antropologia e das ciências sociais. Porém, os estudos dos processos de saúde e doença de uma perspectiva antropológica nem sempre têm sido reconhecidos como formadores de um campo específico dentro da antropologia, e os próprios pesquisadores têm se questionado sobre sua identidade (Minayo, 1998).

Argumentamos neste artigo que a pesquisa antropológica sobre saúde e doença realizada no Brasil tem se multiplicado suficientemente para que se possa identificar a formação de um programa de pesquisa específico no país a partir dos anos 1980. Se comparado à antropologia médica desenvolvida em países do Atlântico Norte, o programa brasileiro de pesquisa mostra tanto uma identidade profissional própria quanto paradigmas teóricos e analíticos singulares. Este trabalho analisa o surgimento desse programa de pesquisa emergente à luz das discussões recentes sobre as antropologias mundiais (Escobar, 2004; Ribeiro, 2006; Ribeiro \& Escobar, 2006). Destacamos os/as antropólogos/as e seus grupos mais atuantes no campo da saúde, bem como as publicações representativas desse programa de pesquisa.

Incluímos pesquisadores/as associados/as tanto aos programas de pós-graduação em antropologia quanto aos programas de saúde pública ou saúde coletiva. Esta última disciplina prosperou com o retorno das políticas democráticas no 
Brasil nos anos 1980, constituindo-se de forma mais significativa a partir de uma ligação estreita com as reflexões e os debates das ciências sociais e políticas do que propriamente em função das discussões epidemiológicas no âmbito da saúde pública. Por fim, trataremos da visibilidade das publicações de pesquisas brasileiras em saúde para examinar a presença desse programa de pesquisa no discurso mais amplo das antropologias médica e da saúde do Atlântico Norte e nos diálogos norte-sul. Procuraremos mostrar que nem sempre uma quantidade maior de publicações resultantes de pesquisas brasileiras, tanto em termos de artigos quanto de periódicos, significa um impacto e/ou um reconhecimento maior da pesquisa em saúde no campo da antropologia de modo geral e nos estudos de antropologia da saúde no plano internacional.

De acordo com Arturo Escobar (2005), os participantes de programas de pesquisa que discutem modernidade e colonialismo na América Latina contestam as ideias universalizantes das ciências sociais e humanas e procuram intervir na discursividade das ciências modernas, buscando pluralizar e descentralizar a produção de conhecimentos e a construção de novos paradigmas. Esses novos paradigmas são resultantes dos "pensamentos de fronteira” e das "epistemologias de fronteira”, que se distinguem, em certa medida, do discurso hegemônico. ${ }^{1}$ A antropologia brasileira - caracterizada por Roberto Cardoso de Oliveira (19992000) como parte das "antropologias periféricas", ou como uma "outra antropologia” segundo Restrepo e Escobar - é por eles considerada uma antropologia que confronta a vertente anglo-americana com mais ênfase do que a maioria das antropologias latino-americanas o faz (Restrepo \& Escobar, 2005:121). Assim, iremos explorar aqui em que extensão se dá essa autonomia teórica dos estudos antropológicos sobre saúde no Brasil e se os seus paradigmas são reconhecidos internacionalmente e se a eles é outorgada autoridade.

\section{Algumas considerações teóricas e conceituais}

Para analisar a expansão e a consolidação da produção de conhecimentos relacionados à antropologia e à saúde, utilizaremos os seguintes conceitos, definidos logo adiante: programa de pesquisa; forças estruturais externas e internas; perfil de interesse; e ethos e valores. Tais conceitos nos permitem identificar tanto a emergência da saúde como um campo de pesquisas antropológicas quanto examinar estruturas de poder, eventos e atores que têm influenciado sua evolução. Além disso, buscamos compreender suas características particulares e saber até que ponto os estudos sobre saúde são reconhecidos no Brasil como uma agenda de pesquisa antropológica legítima. Um "programa de pesquisa”, conforme Escobar, se desenvolve como uma perspectiva emergente e 
significativamente coesa que alimenta uma série de investigações, reuniões, publicações e outras atividades em torno de um conjunto de conceitos compartilhados (2004:31). É necessariamente caracterizado como um programa de escopo multi ou interdisciplinar que se desenvolve em determinado ambiente de pesquisa. Os problemas de pesquisa, teorias, conceitos, métodos e estratégias são negociados entre os pesquisadores dos campos associados de conhecimento, constituindo redes que se estendem além dos tradicionais limites disciplinares, uma vez que os pesquisadores encontram outras áreas que trabalham com os mesmos objetivos, questões e temas. Novas questões de pesquisa, que poderiam ser tomadas como temas marginais ou irrelevantes para os fundamentos e as prioridades de uma disciplina, estimulam a criação de outras relações, fora dos limites disciplinares e das estruturas de poder estabelecidos que orientam a produção de conhecimento.

O desenvolvimento do conhecimento é dependente, em grande medida, das instituições onde as pesquisas são conduzidas. "Forças estruturais externas e internas” podem estimular ou retardar seu avanço, já que afetam a troca criativa de ideias. A ciência está sujeita aos valores sociais e culturais estabelecidos e às estruturas econômicas. As políticas nacionais de educação, o financiamento das universidades e da pesquisa em particular, assim como a estrutura burocrática que está na base do funcionamento destas instituições provocam impactos sobre a dinâmica de produção de conhecimento. Como a estrutura acadêmica é construída a partir de departamentos específicos, organizados por disciplinas e subdisciplinas, grupos de pesquisa temáticos e centros de pesquisa, as interfaces, as margens e os cruzamentos entre as disciplinas são afetados por decisões administrativas tomadas nas instâncias superiores das universidades. Essas decisões resultam em parte de forças de ordem não acadêmica ou externas.

A pesquisa e a pós-graduação nas universidades federais são avaliadas e financiadas através de um sistema altamente centralizado, que envolve duas agências federais e interdependentes de fomento: a Capes (Coordenação de Aperfeiçoamento de Pessoal de Nível Superior), vinculada ao Ministério da Educação, e o CNPq (Conselho Nacional de Desenvolvimento Científico e Tecnológico), vinculado ao Ministério da Ciência e Tecnologia. A Capes credencia, avalia e classifica os programas de pós-graduação através de um processo que interfere fortemente no montante de fundos que será recebido de ambas as agências para cada programa de pós-graduação, o que inclui o número de bolsas concedidas aos estudantes. O CNPq classifica individualmente os pesquisadores e oferece prêmios, na forma de um número limitado de bolsas de produtividade, para aqueles que se destacam nas avaliações da produção acadêmica e dos 
projetos de pesquisa, que é feita com base em revisão por pares. Devido ao número limitado destas bolsas, os pesquisadores do $\mathrm{CNPq}$ formam uma elite pela visibilidade que alcançam na comunidade acadêmica. Além disso, o $\mathrm{CNPq}$ divulga sistematicamente chamadas para financiamento de pesquisas, algumas dirigidas a áreas e a temáticas específicas, outras com temática aberta.

Além das forças estruturais, tanto os perfis de interesse dos pesquisadores quanto o ethos e os valores de um determinado meio acadêmico influenciam o desenvolvimento de um programa de pesquisa. As escolhas individuais e coletivas afetam paradigmas epistemológicos, temas, teorias e métodos que originam as questões de pesquisa.

Um "perfil de interesse" representa a combinação de experiências pessoais e profissionais e também a capacidade do pesquisador de transformar seus interesses em ensino, pesquisa e publicações. Os investigadores são reconhecidos e identificados por seus perfis de interesse. Os candidatos à pós-graduação são atraídos pelos departamentos ou por professores cujos interesses correspondem aos seus interesses pessoais de estudo, obviamente sem descartar outros fatores para a escolha de uma institução ou de um orientador. Como em outras universidades, os perfis de interesse dos professores influenciam na seleção dos alunos e, de certa forma, delimitam os tópicos investigados.

Como uma característica distintiva que marca qualquer antropologia nacional, o ethos ou estilo, juntamente com os valores, é talvez a mais difícil de ser identificada. Segundo Clifford Geertz (1973), o ethos é a dimensão moral e estética da interação coletiva que molda seu estilo, tom ou sua disposição. Joanna Overing $(1989,2003)$ amplia essa noção enfatizando a estética da vida diária, referindo-se à atenção dada às formas e aos desenhos nas habilidades produtivas e sociais. Seguindo estes autores, reconhecemos que a interação social, o estilo da escrita e a constituição de redes no interior da comunidade científica são afetados não somente pelos fundamentos epistemológicos da prática da ciência, mas também pelo ethos e pelos valores coletivos. No caso do Brasil, mais importante do que o uso da língua portuguesa para marcar a distinção, nos parece que sejam as diferentes estéticas e outras dimensões qualitativas que caracterizam a interpretação e a natureza da produção social, evidenciadas na escrita e na constituição das redes sociais entre pesquisadores, como já apontou Luis Roberto Cardoso de Oliveira (2008). O ethos, que é parte integrante da produção de outros conhecimentos (Escobar, 2004), pode se perder ou ser mal entendido na tradução das antropologias.

A produção do conhecimento envolve uma dimensão coletiva que está além das estruturas. Esta produção - as epistemologias; a criação e a renovação de 
conceitos; o surgimento de novos paradigmas; o papel de pensadores seminais; e a interpenetração de ideias - dá origem ao que Escobar tem chamado de uma "mudança epistemológica de perspectiva". Ou seja, o surgimento de um programa de pesquisa depende não só das forças estruturais externas e internas que o moldam, mas também do ambiente interno, de ethos e valores, dos contextos histórico-sociais, políticos e econômicos que trazem para o primeiro plano um "pensamento de fronteira" em diálogo tenso com perspectivas eurocêntricas. Portanto, o crescimento de uma antropologia nacional ou programa de pesquisa não depende somente das epistemologias e dos interesses que circulam entre os seus pesquisadores, nem, podemos acrescentar ainda, da quantidade de pesquisas e publicações realizadas, mas também da estética da produção científica num sentido abrangente.

\section{Os primeiros estudos antropológicos de saúde no Brasil ${ }^{2}$}

Apesar de não ter se constituído nem ter sido percebida como campo de pesquisa na antropologia brasileira durante muitas décadas, a saúde apareceu como tema embutido em discussões sobre folclore, magia, religião e nos estudos de comunidade, entre outros, e em alguns trabalhos esparsos. As diversas revisões que buscam traçar um itinerário desse campo de estudos no Brasil (Canesqui \& Queiroz, 1986; Canesqui, 1986, 2003; Nunes, 1987, 1992, e outros) tem estabelecido diferentes etapas desses anos iniciais de formação, ligadas a distintas abordagens ou escolas teóricas. Não cabe aqui retraçar de forma detalhada essa trajetória, mas resgatar alguns elementos mais gerais desse período, e reter um elemento importante desses primeiros anos, que é o foco nas práticas populares.

Esse foco está presente nas diferentes abordagens marcadas por uma influência evolucionista, como os estudos sobre religião e raça e as interpretações médicas de práticas religiosas populares (Nina Rodrigues, 1897), os estudos de folclore (Cascudo, 1971; Cabral, 1942), que buscavam fazer o inventário das práticas tradicionais, assim como nos primeiros estudos de campo voltados para as medicinas populares, abordando a saúde e as práticas de cura como tradições culturais que tenderiam a desaparecer. Um exemplo tardio desta perspectiva é o capítulo sobre saúde escrito por Charles Wagley no livro Amazon Town (1964 [1953]), no qual ele oferece uma interpretação evolucionista, descrevendo a medicina popular a partir de seus fundamentos na magia e na religião, fadada, portanto, a desaparecer com o avanço da medicina moderna.

Arthur Ramos (1934), antropólogo e psiquiatra, explorou a questão da loucura e do pensamento primitivo, apoiado na psicanálise, de um lado, e nas nas ideias de Lévy-Brühl sobre mentalidade pré-lógica primitiva, de outro. Ele 
explorou este tópico em seus estudos sobre loucura e mentalidade primitiva (1926), culturas e religiões afro-brasileiras, lado a lado com os temas relativos à construção de nação, raça, civilização e educação. Roger Bastide, que teve uma influência importante na formação das ciências sociais no Brasil e de diversos pesquisadores brasileiros, também interessado nas ideias de Lévy-Bruhl, principalmente em sua teoria da participação como lógica central do pensamento primitivo, desenvolveu diversos trabalhos sobre doença mental, psiquiatria social, psicanálise, sonho, transe e loucura, entre outros. ${ }^{3}$ Bastide foi um pioneiro no estudo das relações entre religiões populares e cura.

Elementos de uma abordagem das práticas populares em saúde, colocadas em contraste com a biomedicina, estão presentes de maneira mais ou menos central em trabalhos de vários autores brasileiros publicados entre as décadas de 1940 e 1960 (Mussolini, 1946, 1949; Galvão, 1951, 1952; Araújo, 1977; Fernandes, 1961). Darcy Ribeiro escreveu sobre o impacto das epidemias nas populações indígenas como consequência do contato com os europeus (1956, 1970), a formação da nação brasileira e o processo civilizatório. Contudo, foi sua reformulação das teorias neoevolucionistas (1968), e não os estudos sobre saúde, que contribuiu para uma visão que alguns antropólogos e cientistas sociais consideram como portadora de um projeto alternativo ao paradigma eurocêntrico no âmbito internacional (Meggers, 1968:x; Arruti, 1997; Ribeiro, 2011). Ainda na década de 1960, cabe citar o trabalho de Gilberto Freyre que, em diálogo com uma vertente anglo-saxônica, propõe uma abordagem biocultural articulada entre saúde, doença e cultura e de suas especificidades no ambiente e na cultura dos trópicos como instrumento central para uma política sanitária adaptada à região (Freyre, 1967; Bertolli Filho, 2003).

Uma característica desses anos iniciais das próprias ciências sociais no país, e que irá marcar também os caminhos pelos quais se desenvolve a antropologia da saúde no Brasil a partir dos anos 1970, é a presença e a influência de cientistas sociais e, particularmente, de antropólogos franceses que contribuíram para o crescimento da antropologia brasileira durante esse período. Como consequência dessa proximidade inicial, os autores franceses são mais frequentemente citados pelos cientistas sociais no Brasil, e muitos trabalhos relacionados ao tema da saúde, incluindo os de Boltanski, Bourdieu, Canguilhem, Foucault, Herzlich e Laplantine, foram traduzidos e publicados no Brasil. ${ }^{4} \mathrm{O}$ mesmo não acontece com os autores norte-americanos e britânicos que são referência para a antropologia médica. ${ }^{5}$

Em resumo, o tema da saúde, da doença e das medicinas aparece nesses anos iniciais de forma esparsa, diferenciada e heterogênea nos trabalhos antropológicos 
no Brasil, não constituindo até esse momento um campo de estudos ou um programa de pesquisa propriamente dito.

\section{O período de formação: anos 1970 e 1980}

O período da transição para a democracia, em final dos anos 1970 até a ratificação da nova Constituição Federal brasileira, em 1988, marca uma fase importante para os programas de pós-graduação em antropologia e para o começo dos estudos antropológicos sobre saúde no Brasil. Nessa época foram fundados programas de mestrado em antropologia na Universidade de Brasília (UnB) e no Museu Nacional da Universidade Federal do Rio de Janeiro. Assim, os professores destas duas universidades definiram a agenda de pesquisa em saúde, delineada a partir de conceitos e paradigmas contemporâneos, com poucas referências aos discursos que circulavam na antropologia médica norte-americana.

Um dos projetos preliminares mais relevantes no campo da saúde naquele momento abordou o tema dos hábitos alimentares e da ideologia em diversos segmentos da população brasileira, com participação de antropólogos da UnB e do Museu Nacional (Canesqui \& Queiroz, 1986). O foco desse projeto foi direcionado para as representações culturais e a organização dos hábitos alimentares, analisadas primariamente a partir dos paradigmas do estruturalismo francês e da antropologia simbólica com o fim de entender como as forças políticas e econômicas influenciavam as estratégias de subsistência desses grupos. Foram realizados estudos entre camponeses, comunidades de pescadores e trabalhadores da agricultura e da indústria (Woortmann, 1977).

Entre os pesquisadores do grupo da UnB, Martin Ibáñez-Novión era, possivelmente, aquele que mais se identificava com a antropologia médica do Atlântico Norte (Ibáñez-Novión et al., 1978). Ele começou seu doutorado sob a orientação de Steven Polgar, na Inglaterra, e foi o responsável por introduzir leituras de publicações do campo da antropologia médica para os seus alunos, entre as quais os trabalhos de Byron Good, Arthur Kleinman e Alan Young. ${ }^{6}$ Ibáñez-Novión ajudou a formar um grupo interdisciplinar interessado na interseção entre biologia e antropologia (Ibáñez-Novión \& Ott, 1983) e organizou o primeiro Grupo de Trabalho intitulado "Antropologia Médica” para a Reunião da Associação Brasileira de Antropogia (ABA) de 1984. O assunto não apareceu novamente nas reuniões da ABA até a década de 1990. A visibilidade de Ibáñez-Novión no programa de pesquisa foi breve. Sem terminar seu doutorado, tornou-se marginalizado no programa de pós-graduação da UnB e, embora esta universidade tenha produzido uma série de dissertações de mestrado relevantes para a análise dos hábitos alimentares, os estudos sobre saúde deixaram de ser uma linha de pesquisa por mais de uma década. 
As atividades de pesquisa sobre este tema desenvolvidas no Museu Nacional tiveram maior continuidade. Ao longo da década de 1970, cresce o interesse pelos aspectos simbólicos do corpo, inspirado pelas obras de Marcel Mauss, Mary Douglas e Victor Turner, bem como de estudiosos norte-americanos como Clifford Geertz (Rodrigues, 1975). Em 1979, os etnólogos do Museu Nacional publicam um artigo seminal em que propõem pensar o corpo como o paradigma central para a compreensão das sociedades e das cosmologias ameríndias (Seeger et al., 1987). Este artigo marcou profundamente os primeiros estudos em saúde indígena.

Uma importante linha de trabalho se desenvolveu na década de 1980 no PPGAS do Museu Nacional (UFRJ), dirigida por Gilberto Velho, com foco no tema de indivíduo e sociedade, tendo sido publicados diversos trabalhos voltados para o diálogo entre antropologia e psicanálise (Velho \& Figueira, 1981; Figueira, 1981, 1985) durante um período identificado como de expansão da psicanálise e de uma "cultura psi" na classe média intelectualizada do Rio de Janeiro (Figueira, 1985; Duarte, 1999-2000). Nas pesquisas realizadas nessa linha de trabalho, no campo das sociedades complexas contemporâneas, foram abordados tópicos como vida urbana, modernização, individualismo e estigma, desvio, cultura da psicanálise, atendimento psiquiátrico em camadas populares, entre outros. O próprio Gilberto Velho escreveu sua tese de doutorado sobre o consumo de "tóxicos" nas classes médias no Rio de Janeiro, com foco mais em questões de individualismo e sociabilidade do que no tema das drogas propriamente (Velho, 1998).

Em relação às pesquisas sobre saúde, a figura que mais se destaca nesse grupo do Museu Nacional é Luiz Fernando Dias Duarte. Sua tese de doutorado, publicada em 1986, ${ }^{7}$ é um estudo seminal sobre a "doença dos nervos" e se tornou uma referência clássica para os estudos antropológicos em saúde no Brasil. A pesquisa foca nas noções de perturbação, corpo e pessoa entre segmentos das classes trabalhoras urbanas. É também uma revisão das mais completas sobre os estudos antropológicos brasileiros na área da saúde realizados até a sua publicação. ${ }^{8}$ Duarte se vale explicitamente da tradição da sociologia francesa e é um crítico ativo do que considera o "viés biológico" da antropologia médica norte-americana. Em vários artigos (1993, 1997, 1998a, 1998b, 2003) opõe-se ao que define como "perspectiva empírico-cultural" da antropologia norte-americana sobre os processos e as experiências corporais. Ele propõe a noção de "perturbação", que define como uma experiência físico-moral que escapa às racionalidades biomédica e psicológica, enquanto conceito-chave para os estudos antropológicos em saúde. ${ }^{9}$ 
Também na década de 1980, antropólogos norte-americanos com declarado interesse no campo da saúde emigraram para o Brasil, onde introduziram cursos específicos e formaram grupos de pesquisa sobre o tema em outros programas de pós-graduação. ${ }^{10}$ Por exemplo, na Universidade Federal de Pernambuco (UFPE), Parry Scott foi o precursor dos estudos que articulam saúde, família e pobreza. Em 1986, ele organizou um simpósio que resultou em uma publicação pioneira na antropologia da saúde (Scott, 1986). Esther Jean Langdon, que chegou no Brasil em 1983, introduziu "antropologia médica” como disciplina no ainda Programa de Pós-Graduação em Ciências Sociais, habilitação em antropologia, da Universidade Federal de Santa Catarina (UFSC). Desde lá, diversas dissertações e teses no campo dos estudos antropológicos de saúde foram desenvolvidas no PPGAS da UFSC, com ênfase nos estudos de saúde indígena, constituindo hoje uma das linhas fundamentais de trabalho de vários pesquisadores da UFSC.

Também na década de 1980, Dominique Buchillet, da ORSTROM, França, que trabalhava no Rio Negro, destacou-se como antropóloga importante nas pesquisas em saúde indígena (Buchillet, 1991a). ${ }^{11}$

Até o final dos anos 1980, os antropólogos que pesquisavam temas de saúde não se identificavam com o campo da antropologia médica. Apesar disso, essas pesquisas foram se multiplicando, estimuladas pela criação de políticas públicas e pelo movimento brasileiro da reforma sanitária. Marcos Queiroz (1982) e Maria Andréa Loyola (1984), pesquisadores em saúde com doutorados realizados na Inglaterra e na França respectivamente, voltaram ao Brasil e foram incorporados a escolas de medicina. Nesse período, saúde era tema de dissertações na maioria dos programas de pós-graduação em antropologia, embora poucos pesquisadores se identificassem com o rótulo da antropologia médica. A afiliação de Queiroz e Loyola a programas de medicina social e saúde coletiva reflete uma tendência interdisciplinar no incipiente campo de estudos em saúde, o que se torna uma característica marcante na década de 1990.

Em suma, a pesquisa antropológica em saúde foi crescendo no Brasil a partir de estudos sobre vários tópicos, como medicina popular, "nervos", cultura da psicanálise, mudança nas práticas tradicionais, ideologias e representações, bem como saúde indígena. As primeiras revisões bibliográficas sobre esse campo de conhecimento (Queiroz \& Canesqui, 1986a, 1986b) identificaram as pesquisas como "antropologia da medicina", ou das medicinas, se considerarmos o foco nos estudos das medicinas populares, tradicionais, "religiosas", "eruditas", "medicina oficial moderna" etc., e salientaram a necessidade de se desenvolverem paradigmas capazes de analisar a subordinação ao modelo capitalista de processos 
sociais locais relacionados à saúde. Essas resenhas também afirmaram que paradigmas alternativos à abordagem biológica são fundamentais. Compartilhando esta perspectiva, os antropólogos que pesquisaram no campo da saúde indígena e dialogaram com a biomedicina e as políticas públicas argumentaram sobre a importância dos fatores sociais e culturais na produção ritual do corpo, nos padrões de doença e na cura (Buchillet, 1991b; Verani \& Morgado, 1991).

\section{A consolidação do programa de pesquisa: dos anos 1990 até o presente}

Há um certo consenso na área de que foi na década de 1990 que o programa de pesquisa em antropologia da saúde adquiriu visibilidade no Brasil. ${ }^{12}$ Alguns antropólogos com interesse em saúde retornavam de estudos de doutorado no exterior. Disciplinas de pós-graduação intituladas antropologia da saúde, antropologia da doença e antropologia médica são então oferecidas aos estudantes; e as publicações aumentam em número e diversidade. A investigação dos temas associados à saúde cresce, estimulada por financiamentos com recursos nacionais e internacionais orientados para as políticas de saúde e a agenda global. Consequentemente, os tópicos estudados nos anos 1990 foram semelhantes aos pesquisados fora do Brasil, tais como gênero; saúde reprodutiva e sexualidade; HIV/AIDS; violência; abuso de drogas e outras substâncias; saúde mental; serviços primários de saúde; terapias alternativas; etnia e raça; e ética.

Em 1993 realizou-se o primeiro Encontro Nacional em Antropologia Médica, reforçando a consolidação de uma rede de investigadores. A diversidade de temas foi expressiva, tratando de saúde e religião; "saúde mental", "nervos" e problemas psicossociais; relações dialéticas entre sujeito e objeto no campo das terapêuticas e da própria produção da enfermidade; e questões presentes no campo profissional de produção de agentes e de práticas terapêuticas (Alves \& Minayo, 1994:10). A associação de temas de saúde a temas antropológicos clássicos era evidente (Carrara, 1994). Um segundo encontro nunca chegou a acontecer e, ao contrário dos antropólogos norte-americanos e europeus, no Brasil não se estabeleceu uma associação formal específica para os pesquisadores em antropologia da saúde, nem se criou uma revista especializada. ${ }^{13}$ No entanto, desde o encontro em 1993, a rede de antropólogos que trabalham nesse campo se multiplicou e sua participação em eventos nacionais intensificou-se.

A expansão do programa de pesquisa em antropologia da saúde, ao longo da década de 1990, acompanhou o desenvolvimento de programas de doutorado em todo o país. Essa política educacional foi conduzida a fim de reduzir a dependência da Europa e da América do Norte na formação avançada de pesquisadores 
brasileiros. O número de programas de doutorado em antropologia aumentou de três, em 1989, para 12, em 2009. Os antropólogos que trabalham com temas relacionados à saúde estão distribuídos entre esses programas de antropologia, os institutos e os departamentos de pós-graduação em saúde coletiva, ou em organizações governamentais e não governamentais que prestam serviços de saúde à população.

A Tabela 1 apresenta os programas de doutorado em antropologia com grupos de pesquisa em temas de saúde. Não estão incluídos os grupos listados no diretório de pesquisa do $\mathrm{CNPq}$ vinculados a programas que não oferecem doutorado. Esses dados se concentram nos pesquisadores do $\mathrm{CNPq}$ devido à sua visibilidade, mas não excluem outros pesquisadores.

Algumas observações se fazem necessárias para uma compreensão do contexto político interno às universidades e à pós-graduação no Brasil e das consequentes disputas de poder, bem como da forte ligação que a antropologia brasileira tem com a "antropologia clássica”. O PPGAS do Museu Nacional (UFRJ), um dos dois programas mais bem classificados pela Capes, continua contribuindo para as pesquisas em saúde, porém, como nas décadas de 1970 e 1980, seus pesquisadores permanecem sem se alinhar com as teorias da antropologia médica ou com as da antropologia da saúde. Luiz Fernando Duarte, um dos principais investigadores do Museu Nacional, vem desenvolvendo uma abordagem teórica orientada para as relações sociais e a "construção da pessoa", que se reflete nos trabalhos que orienta e nas pesquisas de seus ex-alunos.

A consolidação de novos grupos de pesquisa na década de 1990 foi reforçada por pesquisadores que realizaram estudos de doutorado no exterior e posteriormente retornaram às suas respectivas universidades no país, incluindo a Universidade Federal do Rio Grande do Sul (UFRGS), a Universidade da Bahia (UFBA) e a Universidade de São Carlos (UFSCar). Eles têm se destacado por introduzir paradigmas sociológicos e do Atlântico Norte nos estudos antropológicos sobre saúde, tais como doença-illness, disease e sickness - experiência, narrativa, fenomenologia e teorias do corpo (Alves, 1993, 2006; Alves \& Rabelo, 1997; Rabelo et al., 1999; Leal, 1995), de um lado, e as discussões sobre antropologia da doença e os sentidos sociais da doença, de outro.

Grupos de pesquisa da UFRGS, da UFPE e da UFSC têm estabelecido cooperação com organizações governamentais e não governamentais envolvidas em causas sociais e legais, além da colaboração interdisciplinar com as ciências biomédicas e com as psicologias. 


\begin{tabular}{|c|c|c|c|}
\hline $\begin{array}{l}\text { Universidade e inicio do } \\
\text { Programa de Dcutorado }\end{array}$ & $\begin{array}{l}\text { Núcleos de pesquisa em saúde } \\
\text { atuais e ano de origem de } \\
\text { pesquisas em saúde }\end{array}$ & Linhas de pesquisa em saúde & Palavras-chave \\
\hline Museu Nacional/UFRJ -1980 & $\begin{array}{l}1970-75 \text { - Núcleo de } \\
\text { Pesquisa sobre Sujeito, } \\
\text { Interaçào e Mudança: } \\
\text { pessoa, familia e religilio }\end{array}$ & $\begin{array}{l}\text { Familia, reproduçá e } \\
\text { ethos religioso no Brasil }\end{array}$ & $\begin{array}{l}\text { Corpo, saúde mental, } \\
\text { psicanálise; medicina e } \\
\text { ciência; género, reproduçâ, } \\
\text { saúde e pessoa; } \\
\text { homossexualidade }\end{array}$ \\
\hline UFSC - 1999 & $\begin{array}{l}1983 \text { - Núcleo de Estudos } \\
\text { sobre Saúde e Saberes } \\
\text { Indigenas (NESSI); Núcleo de } \\
\text { Antropologia do } \\
\text { Contemporâneo (TRANSES) }\end{array}$ & $\begin{array}{l}\text { Saúde, doença e corporeidade; } \\
\text { Parentesco, familia, gênero e } \\
\text { sexualidade; } \\
\text { Subjetividade, micropolitica e } \\
\text { movimentos contemporaneos; } \\
\text { Politicas pubblicas e sociais, } \\
\text { justica e direilos humanos }\end{array}$ & $\begin{array}{l}\text { medicamentos; religias; } \\
\text { gênero; saúde indigena; } \\
\text { politicas públicas; medicina } \\
\text { popular; hospitais e } \\
\text { instituiçø̋es médicas; saúde } \\
\text { mental; biopolitica }\end{array}$ \\
\hline UFPE -2000 & $\begin{array}{l}1980 \text { - Núcleo de Familia, } \\
\text { Género e Sexualidade; } \\
\text { Saúde Reprodutiva e } \\
\text { Populaçdes Indigenas }\end{array}$ & Familla, gênero e sexualidade; & $\begin{array}{l}\text { Saúde da comunidade, } \\
\text { pobreza, sexualidade, } \\
\text { familia, saúde indigena }\end{array}$ \\
\hline UFRGS - 1992 & $\begin{array}{l}1992 \text { - Núcleo de Pesquisa } \\
\text { em Antropologia do Corpo e } \\
\text { da Saúde (NUPACS) }\end{array}$ & Gênero, corpo e saúde & $\begin{array}{l}\text { Género, saúde reprodutiva, } \\
\text { corpo, alimentaçao }\end{array}$ \\
\hline $\begin{array}{l}\text { UFBA - Doutorado em Ciências } \\
\text { Sociais - } 1999\end{array}$ & $\begin{array}{l}1990 \text { - Núcleo de Estudos } \\
\text { em Ciências Sociais, } \\
\text { Ambiente e Saúde } \\
\text { (ECSAS) }\end{array}$ & $\begin{array}{l}\text { Cultura, identidade e } \\
\text { corporeidade }\end{array}$ & $\begin{array}{l}\text { Gênero, familia, raça e } \\
\text { saúde; Experiência de } \\
\text { doença, narrativas e } \\
\text { processos terapétuticos; } \\
\text { Saúde, sociedade e } \\
\text { cultura; Medicina e } \\
\text { literatura }\end{array}$ \\
\hline $\begin{array}{l}\text { UFBA - } 2007 \\
\text { Anteriormente parte do } \\
\text { Doulcrado em Ciéncias Sociais }\end{array}$ & $\begin{array}{l}\text { Corpo, Sexualidades, Saúde e } \\
\text { Saberes Teraptuticos; Grupo } \\
\text { Interdisciplinar sobre Estudos } \\
\text { de Substancias Psicoativas; } \\
\text { Núcleo de Estudos } \\
\text { Interdisciplinares sobre a } \\
\text { Mulher }\end{array}$ & $\begin{array}{l}\text { Encruzilhada de Saberes: } \\
\text { cultura, corpo, saúde e } \\
\text { ecologia; dor, sofrimento, } \\
\text { cuidado e sistemas } \\
\text { terapêticos }\end{array}$ & $\begin{array}{l}\text { Saúde indigena, saúde } \\
\text { popular, reproduç̧a, } \\
\text { saúde mental; ritos de } \\
\text { cura, terapias, género }\end{array}$ \\
\hline $\begin{array}{l}\text { UFSCar - } 2009 \\
\text { Anteriormente parte do } \\
\text { Doutorado em Clencias Sociais }\end{array}$ & $\begin{array}{l}1999 \text { - Modelos terapeuticos, } \\
\text { politicas de saúde, práticas } \\
\text { corporais e a imvestigação } \\
\text { antropológica }\end{array}$ & $\begin{array}{l}\text { Antropologia da Saúde, } \\
\text { do Esporte e } \\
\text { Corporalidade }\end{array}$ & $\begin{array}{l}\text { Saúde indigena, saúde } \\
\text { mental; } \\
\text { Pessoa e subjetividade }\end{array}$ \\
\hline UnB -1981 & $\begin{array}{l}2000 \text { - Antropologia } \\
\text { Pollitica da Saúde }\end{array}$ & Antropologia da saúde & $\begin{array}{l}\text { Gênero, politicas públicas, } \\
\text { saúde indigena }\end{array}$ \\
\hline $\begin{array}{l}\text { UNICAMP - } 2004 \\
\text { Antericmente parte do } \\
\text { Doutorado em Ciências Sociais }\end{array}$ & $\begin{array}{l}1990 \text { - Sexualidade, Género e } \\
\text { Corpo: Envelhecimento e } \\
\text { relaçes de poder }\end{array}$ & Sem linha correspondente & $\begin{array}{l}\text { Corpo e técnicas de } \\
\text { rejuvenescimento; genero e } \\
\text { envelhecimento; violència } \\
\text { doméstica }\end{array}$ \\
\hline UFPA - 2010 & $\begin{array}{l}2000 \text { - Antrcpologia, } \\
\text { Religila e Saúde }\end{array}$ & $\begin{array}{l}\text { Socioecologia da } \\
\text { saúde e da doença }\end{array}$ & Simbolismo, religis̄o, saûde \\
\hline
\end{tabular}


A partir dos anos 1990, os antropólogos formados no Brasil estão cada vez mais se filiando a programas de pós-graduação em medicina preventiva, medicina social, saúde pública e saúde coletiva. O campo da saúde coletiva, no Brasil, cresceu alimentado pelo movimento da reforma sanitária que acompanhou a transição para a democracia, a favor do estabelecimento do Sistema Único de Saúde (SUS), nos anos 1980 (Canesqui, 2008; Loyola, 2008; Nunes, 2006). Ele se diferencia da saúde pública, cujo foco teórico é a epidemiologia, e tem ligação com os movimentos políticos de reforma sanitária em toda a América Latina. A saúde coletiva se caracteriza como um campo de pesquisa mais politizado e interdisciplinar, que se desenvolveu a partir da década de 1980. As ciências sociais têm feito contribuições importantes a este campo. ${ }^{14}$

A Tabela 2 apresenta os programas de doutorado em saúde que têm antropólogos em seus quadros. Utilizamos as palavras-chave "antropologia e saúde coletiva" para fazer a busca no diretório de Grupos de Pesquisa do CNPq, e assim identificamos 21 grupos de pesquisa, porém, nem todos são liderados por antropólogos.

\section{Constituição de redes: reuniões, conferências e congressos}

O campo antropológico brasileiro, além da esfera institucional dos Departamentos e dos Programas de Pós-Graduação, é formado por redes de pesquisadores em torno de temas comuns, projetos ou mesmo encontros sistemáticos nos congressos da área, além de conferências e eventos pontuais. A Associação Brasileira de Antropologia (ABA) mantém reuniões bianuais e os eventos regionais são realizados em anos alternados, sendo os principais o Encontro dos Antropólogos do Norte e Nordeste (Abanne) e a Reunião de Antropologia do Mercosul (RAM). Ambos são compostos por participantes de outros países latino-americanos. A RAM é um grande evento regional que se realiza alternadamente em cidades da Argentina, do Uruguai e do Brasil. Em todos esses eventos, o número de sessões dedicadas ao tema da saúde tem aumentado significativamente ao longo do tempo.

Outro fórum acadêmico importante no campo das ciências sociais é a Reunião da Associação Nacional de Pós-Graduação e Pesquisa em Ciências Sociais (Anpocs), fundada em 1977. Na década de 1980, houve tentativas para incluir neste fórum um grupo intitulado "Saúde e Sociedade", que seria composto por sociólogos, antropólogos e pesquisadores da área de saúde coletiva. A proposta foi rejeitada duas vezes pela Anpocs, com a alegação de que seria um debate mais adequado para a Associação da Saúde Coletiva (Minayo, 1998). O primeiro grupo aprovado na Anpocs para discutir temas de saúde, o simpósio 
“Corpo, Pessoa e Doença”, estava voltado para os debates antropológicos clássicos e para a articulação de questões de saúde com a discussão antropológica sobre corpo e pessoa, e foi coordenado por Luiz Fernando Dias Duarte na década de 1990.

\section{Tabela 2: Programas de Doutorado em Saúde com participação de antropólogos}

\begin{tabular}{|c|c|c|}
\hline Programas de Doutorado em Saúde & Grupos de pesquisa atuais & Palavras-chave \\
\hline $\begin{array}{l}\text { Instituto de Medicina Social/Univ. } \\
\text { Estadual do Rio de Janeiro (UERJ) }\end{array}$ & $\begin{array}{l}\text { Gênero, sexualidade e saúde; } \\
\text { Instituiçōes de saúde e } \\
\text { representaçōes; } \\
\text { Conhecimento, práticas biomédicas } \\
\text { e a produçāo de identidades; } \\
\text { Institucionalização de } \\
\text { conhecimento psicológico no Brasil }\end{array}$ & $\begin{array}{l}\text { Sexualidade; instituiçōes } \\
\text { médicas; psicanálise no } \\
\text { Brasil; familia; AIDS; } \\
\text { medicina popular; } \\
\text { medicamentos; gênero; } \\
\text { juventude; cidadania; } \\
\text { cuidados e cura; doença, } \\
\text { diagnóstico e identidade }\end{array}$ \\
\hline $\begin{array}{l}\text { Departamento de Medicina } \\
\text { Preventiva e Social/ } \\
\text { UNICAMP }\end{array}$ & $\begin{array}{l}\text { Saúde, memória e sociedade: } \\
\text { Cultura, saúde e doença }\end{array}$ & $\begin{array}{l}\text { Sociologia da saúde; } \\
\text { nutriçăo e antropologia; } \\
\text { serviços de saúde; ensino } \\
\text { das ciências sociais em } \\
\text { programas de saúde; } \\
\text { saúde e medicina; } \\
\text { representaçð̄es de saúde e } \\
\text { doença; relaç̋̄es de } \\
\text { trabalho em saúde }\end{array}$ \\
\hline $\begin{array}{l}\text { ENSP/FIOCRUZ/Rio de Janeiro } \\
\text { (com centros em } \\
\text { Manaus e Rondônia) }\end{array}$ & $\begin{array}{l}\text { Saúde, epidemiologia e } \\
\text { antropologia dos povos indigenas; } \\
\text { Estudos socioculturais do processo } \\
\text { de saúde-doença-terapia; } \\
\text { Violência e saúde; } \\
\text { Saúde pública e envelhecimento }\end{array}$ & $\begin{array}{l}\text { Saúde indigena; violência; } \\
\text { antropologia médica; } \\
\text { nutrição e hábitos } \\
\text { alimentares; demografia; } \\
\text { antropologia do } \\
\text { envelhecimento; psiquiatria } \\
\text { cultural; metodologia } \\
\text { qualítativa; epidemiologia e } \\
\text { biologia das populaçóes } \\
\text { indigenas }\end{array}$ \\
\hline Instituto de Saúde Coletiva/ UFBA & & $\begin{array}{l}\text { DST/AIDS; antropologia da } \\
\text { saúde; corpo; gênero; } \\
\text { consumo de esteroides } \\
\text { anabolicos; saúde mental; } \\
\text { violência urbana; simbolos } \\
\text { e práticas de saúde; } \\
\text { terapias tradicionais e } \\
\text { metodologia }\end{array}$ \\
\hline
\end{tabular}

A Associação Brasileira de Pós-Graduação em Saúde Coletiva (Abrasco), fundada em 1979, promove regularmente reuniões sobre saúde coletiva, organizadas junto com o Fórum Latino-Americano e Internacional de Ciências Sociais e Saúde. Estes eventos têm sido decisivos tanto para o crescimento do programa de pesquisa quanto para a formação de uma rede de investigadores 
com conexões fora do Brasil. A Abrasco tem grandes reuniões anuais, que se alternam entre as áreas de epidemiologia, saúde coletiva e ciências sociais e saúde, sendo que todos os anos há sessões individuais e workshops com antropólogos. O primeiro Congresso Brasileiro de Ciências Sociais e Humanas em Saúde (da Abrasco) foi realizado em novembro de 1995 (Canesqui, 1995). O segundo, que aconteceu em 1999, foi agregado ao Fórum Latino-Americano de Ciências Sociais e Saúde e resultou em um volume editado por Goldenberg, Marsiglia e Gomes, em 2003. Esta coletânea traz artigos sobre os temas de ciências sociais e saúde; cultura e subjetividade; diversidade metodológica; desigualdades e diferenças nas condições de saúde; saúde indígena; raça e etnia; prevenção; relações entre os setores público e privado; fragmentação social e formas de solidariedade; e qualidade de vida, violência e saúde. O terceiro congresso foi realizado em Florianópolis, Santa Catarina, em 2005 (Camargo Jr., 2005); o quarto aconteceu em 2007, em conjunto com o X Congresso Latino-Americano de Medicina Social, em Salvador, Bahia; o quinto foi efetivado em 2011, em São Paulo; e o sexto deverá acontecer em 2013, no Rio de Janeiro.

O Fórum Internacional de Ciências Sociais e Saúde, realizado em países da América Latina, conta com a participação de antropólogos brasileiros. Em 1994, de uma reunião realizada na Venezuela publicou-se uma coletânea com uma seção sobre ciências sociais da saúde no Brasil (Briceño-León, 1999). Em 1999, o V Congresso Latino-Americano de Ciências Sociais e Saúde, que também aconteceu na Venezuela, resultou em um volume publicado no Brasil (BriceñoLeón et al., 2000). Em 2003, o VII Congresso Latino-Americano de Ciências Sociais e Saúde, realizado no Brasil, originou um volume de artigos selecionados (Minayo \& Coimbra Jr., 2005). Estas coleções são representativas dos diversos tópicos de interesse do programa de pesquisa e refletem o crescimento de uma rede de antropólogos, outros cientistas sociais e profissionais da área médica.

\section{Publicações}

A Escola Nacional de Saúde Pública Sérgio Arouca, da Fundação Oswaldo Cruz (ENSP/Fiocruz), tem desempenhado um papel fundamental na publicação de pesquisas antropológicas sobre saúde devido aos esforços de Carlos Coimbra Jr. e Maria Cecília Minayo. Uma de suas publicações centrais são os Cadernos de Saúde Pública, um periódico dos mais bem classificados no Brasil na área de saúde pública. Em 1991, esta revista editou um número especial sobre saúde indígena, trazendo alguns artigos escritos por antropólogos (Coimbra, 1991). Em 1993, uma segunda edição especial tratou da abordagem antropológica em saúde (Minayo \& Coimbra, 1993). Em 1994, a Editora Fiocruz publicou dois 
livros sobre antropologia e saúde (Alves \& Minayo, 1994; Santos \& Coimbra, 1994). Em 1998, esta editora deu início à coleção Antropologia e Saúde, que já conta com 21 títulos até o momento. Coimbra e seus colegas, que trabalham na saúde indígena, têm editado numerosos artigos e livros pela editora da Fiocruz e, em 2003, lançaram uma coleção sobre saúde dos povos indígenas, com três títulos até o momento.

O periódico Ciência e Saúde Coletiva, da Abrasco, tem veiculado debates relevantes e oportunos sobre a contribuição das ciências sociais para a saúde, em temas variados como violência, AIDS, serviços de saúde, entre outros. Muitos autores que publicam na revista são de outros países latino-americanos e, embora a língua principal seja o português, alguns textos são escritos em espanhol. Tanto a revista Ciência e Saúde Coletiva quanto a Cadernos de Saúde Pública começaram, recentemente, a incluir artigos em inglês, com o intuito de favorecer o diálogo com os cientistas da América do Norte e da Europa.

O Instituto de Medicina Social da Universidade Estadual do Rio de Janeiro (UERJ) publica a Physis: Revista de Saúde Coletiva desde 1991, que também recebe um grande número de trabalhos de antropólogos brasileiros e estrangeiros. Artigos sobre antropologia e saúde estão presentes na Revista de Saúde Pública, da Universidade de São Paulo (USP) e na Saúde e Sociedade, uma revista interdisciplinar publicada conjuntamente pela Faculdade de Saúde Pública da USP e pela Associação Paulista de Saúde Pública.

Apesar de não existir no Brasil uma revista de antropologia especializada em estudos de saúde, este tema tem aparecido em números temáticos de alguns periódicos da área. A Horizontes Antropológicos, da UFRGS, lançou três edições especiais sobre sexualidade, saúde e corpo, organizadas por membros do Nupacs (Leal, 1998; Knauth \& Víctora, 2002; Victora et al., 2006). A Revista Ilha, da UFSC, produziu recentemente um número temático sobre religião e cura (Groisman, 2005), com artigos apresentados na Mesa Redonda do encontro da Abrasco de 2005. Outros periódicos publicados por programas de pós-graduação de antropologia, como a prestigiada Mana, do Museu Nacional, a Revista de Antropologia, da USP, o Anuário Antropológico, da UnB, Mediações: Revista de Ciências Sociais, da UEL, e a Tellus, vinculada a um núcleo de pesquisa sobre populações indígenas da UCDB, vêm publicando um número crescente de artigos sobre saúde, e a Vibrant, periódico electrônico editado pela ABA, apresenta de forma esparsa artigos baseados em estudos antropológicos sobre saúde. ${ }^{15}$

Por um lado, esse crescimento da produção de artigos e de pesquisas sobre antropologia e saúde evidencia a consolidação e a importância desse programa de pesquisa no Brasil, mas uma pergunta a ser feita neste balanço do campo é sobre 
que impacto tem essa produção no plano internacional. Um indicador interessante para essa discussão é trazer alguns dados e análises sobre artigos a respeito de saúde que são editados em periódicos nacionais e estrangeiros, sua circulação, indexação e inclusão em bases de dados, distribuição das referências, entre outros.

\section{Visibilidade das revistas brasileiras}

Para avaliar a visibilidade das pesquisas brasileiras em antropologia da saúde no circuito internacional, utilizamos métodos bibliométricos. ${ }^{16} \mathrm{~A}$ maioria dos bancos de dados é produzida nos EUA e na Europa, e neles as revistas latino-americanas pouco apareciam até recentemente, o que mudou na última década (Biblioteca Virtual em Saúde, 2008). Em 1997, a Scientific Electronic Library Online - SciELO - lançou um portal brasileiro a fim de melhorar a comunicação científica entre países em desenvolvimento do Cone Sul, especialmente da América Latina e do Caribe. O objetivo da SciELO é publicar online periódicos científicos brasileiros que disponibilizem artigos com texto completo e permitam acesso livre e universal aos seus conteúdos, para superar o fenômeno caracterizado por Gibbs (1995) como "ciência perdida”. Para serem incluídas nesta base de dados virtual, as revistas são avaliadas tanto por seu mérito científico quanto pela regularidade e qualidade da produção científica que veiculam.

Em março de 2009, o portal brasileiro da SciELO incluiu 193 títulos de todos os campos de conhecimento. Atualmente, a rede SciELO é constituída por portais completos para oito países, além de sete novos portais em construção e duas coleções temáticas em saúde pública e ciências sociais. No total, abriga 473 periódicos de 12 países íbero-americanos e um do Caribe (Meneghini, 2007). ${ }^{17}$ Ao ser selecionado para publicação na SciELO, um periódico alcança visibilidade dentro e fora do país.

A Tabela 3 informa sobre o acesso aos periódicos mencionados acima que têm publicado artigos relevantes para o programa de pesquisa. Destes, apenas três não estão na SciELO e um, a Revista de Antropologia, da USP, está com a indexação interrompida desde 2007.

A pressão para publicar se tornou uma grande força interna na academia brasileira ao longo dos últimos 15 anos. A produtividade é central nas avaliações conduzidas pela Capes e pelo CNPq para classificar e hierarquizar os programas de pós-graduação e agraciar pesquisadores. Nos últimos dez anos, as equipes de avaliação que trabalham para essas agências têm se esforçado na construção de escalas para classificar as publicações, o que deve permanecer na pauta de discussão dos avaliadores nos próximos anos. Atualmente, a tendência é de se atribuir melhor classificação para publicações em revistas internacionais. 
Tabela 3: Revistas de Saúde e Antropologia mencionadas nesta pesquisa

\begin{tabular}{|c|c|c|c|c|c|}
\hline Titulo & ISSN & Editora & Ano de inicio & Campo principal & Acesso \\
\hline $\begin{array}{l}\text { Cadernos de } \\
\text { Saúde Pública }\end{array}$ & $\begin{array}{l}0102-311 X \\
678-4464(e)\end{array}$ & $\begin{array}{c}\text { Escola Nacional de } \\
\text { Saúde Pública }\end{array}$ & 1980 & Saúde pública & $\begin{array}{l}\text { impresso/ } \\
\text { acesso virtual }\end{array}$ \\
\hline $\begin{array}{l}\text { Ciência \& } \\
\text { Saúde Coletiva }\end{array}$ & $\begin{array}{c}1413-8123 \\
1678-4561(\mathrm{e})\end{array}$ & $\begin{array}{l}\text { Associaçâo Brasileira } \\
\text { de Pós- } \\
\text { Graduaçấ em Saúde } \\
\text { Coletiva }\end{array}$ & 1996 & Saude coletiva & $\begin{array}{l}\text { impresso/ } \\
\text { acesso virtual }\end{array}$ \\
\hline $\begin{array}{l}\text { Physis: Revista de } \\
\text { Saúde Coletiva }\end{array}$ & $\begin{array}{c}0103-7331 \\
1809-4481(e)\end{array}$ & $\begin{array}{l}\text { Universidade do } \\
\text { Estado do Rio de } \\
\text { Janeiro, Instituto de } \\
\text { Medicina Social }\end{array}$ & 1991 & $\begin{array}{l}\text { Saúde coletiva } \\
\text { e ciências socials }\end{array}$ & $\begin{array}{l}\text { impresso/ } \\
\text { acesso virtual }\end{array}$ \\
\hline $\begin{array}{l}\text { Revista de } \\
\text { Saúde Pública }\end{array}$ & $\begin{array}{c}0034-8910 \\
1518-8787 \text { (e) }\end{array}$ & $\begin{array}{l}\text { Universidade de } \\
\text { Sao Paulo, } \\
\text { Faculdade de } \\
\text { Saude Pública }\end{array}$ & 1947 & Saúde pública & $\begin{array}{l}\text { impresso/ } \\
\text { acesso virtual }\end{array}$ \\
\hline $\begin{array}{l}\text { Saude e } \\
\text { Sociedade }\end{array}$ & $\begin{array}{c}0104-1290 \\
1984-0470(\mathrm{e})\end{array}$ & $\begin{array}{c}\text { Universidade de São } \\
\text { Paulo, } \\
\text { Faculdade de Saude } \\
\text { Pública }\end{array}$ & 1991 & Saúde pública & $\begin{array}{l}\text { impresso/ } \\
\text { acesso virtual }\end{array}$ \\
\hline $\begin{array}{l}\text { Horizontes } \\
\text { Antropológicos }\end{array}$ & $\begin{array}{c}0104-7183 \\
1806-9983(e)\end{array}$ & $\begin{array}{l}\text { Universidade } \\
\text { Federal } \\
\text { do Rio Grande do } \\
\text { Sul }\end{array}$ & 1994 & Antropologia & $\begin{array}{l}\text { impresso/ } \\
\text { acesso virtual }\end{array}$ \\
\hline Revista Itha & $1517-395 x$ & $\begin{array}{l}\text { Universidade Federal de } \\
\text { Santa Catarina, } \\
\text { Departamento de } \\
\text { Antropologia }\end{array}$ & 1999 & Antropologia & $\begin{array}{l}\text { impresso/ } \\
\text { acesso virtual }\end{array}$ \\
\hline Mana & $\begin{array}{c}0104-9313 \\
1678-4944(e)\end{array}$ & $\begin{array}{l}\text { Universidade Federal do } \\
\text { Rio de Janeiro, } \\
\text { Depto. de Antropologia }\end{array}$ & 1995 & Antropologia & $\begin{array}{l}\text { impresso/ } \\
\text { acesso virtual }\end{array}$ \\
\hline $\begin{array}{l}\text { Revista de } \\
\text { Antropologia }\end{array}$ & $\begin{array}{c}0034-7701 \\
1678-9857(e)\end{array}$ & $\begin{array}{l}\text { Universidade } \\
\text { de Sao Paulo }\end{array}$ & 1953 & Antropologia & $\begin{array}{l}\text { impresso' } \\
\text { acesso virtual }\end{array}$ \\
\hline $\begin{array}{l}\text { Anúario } \\
\text { Antropológico }\end{array}$ & $0102-4302$ & $\begin{array}{l}\text { UnB/Ediçces } \\
\text { Tempo Brasileiro }\end{array}$ & 1976 & Antropologia & impresso \\
\hline Tellus & $1519-9452$ & $\begin{array}{l}\text { Universidade Catolica } \\
\text { Dom Bosco, Programa } \\
\text { Kaiowa-Guarani }\end{array}$ & 2001 & Antropologia & $\begin{array}{l}\text { impresso/ } \\
\text { acesso virtual }\end{array}$ \\
\hline $\begin{array}{l}\text { Vibrant, Brazilian } \\
\text { Virtual Anthropology }\end{array}$ & $1809-4341(e)$ & $\begin{array}{l}\text { Associaçao Brasleira } \\
\text { de Antropologia }\end{array}$ & 2004 & Antropologia & Acesso virtual \\
\hline
\end{tabular}

Fonte: Ulrich’s Periodicals Directory, Latindex Catálogo

Outra medida de visibilidade é a presença dos periódicos acadêmicos em indexadores internacionais relevantes. A Tabela 4 mostra a relação de revistas brasileiras em seis dessas bases de dados: Medline, Web of Science, Scopus, Sociological Abstract, Lilacs (Literatura Latino-Americana e do Caribe em Ciências da Saúde) e SciELO. As revistas com livre acesso a todo o seu conteúdo 
alcançam visibilidade internacional, apesar de as revistas da área de saúde pública apresentarem uma visibilidade maior do que aquelas da área de antropologia.

\section{Tabela 4: Revistas Brasileiras Indexadas}

\begin{tabular}{|c|c|c|c|c|c|c|c|}
\hline Título & Medline & $\begin{array}{l}\text { Web of } \\
\text { Science }\end{array}$ & Scopus & $\begin{array}{c}\text { Sociological } \\
\text { Abstracts }\end{array}$ & Lilacs & SciELO & $\begin{array}{c}\text { Capes } \\
\text { Antro/Saúde Pública }\end{array}$ \\
\hline $\begin{array}{l}\text { Cadernos de } \\
\text { Saúde Pública }\end{array}$ & $x$ & 2007 - & 1998 - & $x$ & $x$ & $x$ & $\mathrm{~A} 1 / \mathrm{A} 2$ \\
\hline $\begin{array}{c}\text { Ciência \& } \\
\text { Saúde Coletiva }\end{array}$ & $x$ & 2008 - & 2002 - & $x$ & $x$ & $x$ & $-/ B 1$ \\
\hline $\begin{array}{l}\text { Physis: Revista } \\
\text { de Saúde Coletiva }\end{array}$ & & & 2005 - & $x$ & $x$ & $x$ & B3/B1 \\
\hline $\begin{array}{c}\text { Revista de } \\
\text { Saúde Pública }\end{array}$ & $x$ & 1985 . & 1967 - & & $x$ & $x$ & $-/ A 2$ \\
\hline $\begin{array}{l}\text { Saúde e } \\
\text { Sociedade }\end{array}$ & & 2008 - & 2003 - & $x$ & $x$ & $x$ & $\mathrm{~B} 2 / \mathrm{B} 3$ \\
\hline $\begin{array}{c}\text { Horizontes } \\
\text { Antropológicos }\end{array}$ & & & 2004 - & $x$ & & $x$ & A1/B5 \\
\hline Revista Itha & & & & & & & $\mathrm{B} 3 /$ - \\
\hline Mana & & 2007 - & 1996 - & $x$ & & $x$ & $\mathrm{~A} 1 / \mathrm{B} 2$ \\
\hline $\begin{array}{c}\text { Revista de } \\
\text { Antropologia }\end{array}$ & & & $\begin{array}{l}1996- \\
2007\end{array}$ & $x$ & & $x$ & A1/ - \\
\hline $\begin{array}{c}\text { Anuário } \\
\text { Antropológico }\end{array}$ & & & & & & & B1/ - \\
\hline Tellus & & & & & & & $\mathrm{A} 1 /$ - \\
\hline $\begin{array}{l}\text { Vibrant, Brazilian } \\
\text { Virtual Anthropology }\end{array}$ & & & & & & & B1/ - \\
\hline
\end{tabular}

Fonte: Ulrich's Periodicals Directory, Latindex Catálogo, Capes - Qualis 2007

Conforme ilustra a Tabela 4, alguns periódicos da área médica ou de saúde pública aparecem no Sociological Abstracts, o que indica seu perfil interdisciplinar. Por outro lado, os dois periódicos antropológicos que constam nesses indexadores não estão presentes nos indexadores da área de saúde. Uma das primeiras revistas de antropologia lançadas no Brasil, o Anuário Antropológico da UnB, não aparece em qualquer dessas bases.* A Revista de Antropologia, da USP,

* Nota dos Editores: Até o ano de 2010 o Anuário Antropológico tinha periodicidade anual, não se enquadrando, portanto, nos padrões convencionados pelos indexadores. Somente nos últimos dois anos foi possível dar início ao processo de indexação internacional, uma vez que sua periodicidade tornou-se semestral. 
o mais antigo periódico antropológico brasileiro, fundado em 1953, esteve indexado em duas bases, mas sua indexação na SciELO foi interrompida porque não conseguiu manter uma periodicidade regular de publicação.

A Figura 1 é uma análise de agrupamentos ${ }^{18}$ que utiliza escalonamento multidimensional, o qual examina a direção e a distribuição de referências cruzadas em 15 revistas estrangeiras e brasileiras, com base nos dados do Scopus ${ }^{19}$ para artigos publicados entre 2000 e 2009. As revistas brasileiras, que aparecem como círculos cinza claro, são as mesmas listadas acima com a cobertura completa no Scopus. As revistas estrangeiras selecionadas, marcadas como círculos cinza escuro, são aquelas que representam a antropologia médica ou da saúde do Atlântico Norte. A espessura das setas direcionais, bem como a proximidade entre elas indicam o número de referências à outra revista em relação ao número total de publicações na revista citada. O tamanho dos pontos aponta o número total de publicações em cada número de revista durante o período.

A análise demonstra que as revistas brasileiras tendem a se agrupar separadamente das revistas estrangeiras, denunciando um intercâmbio limitado entre as nacionais e as outras. As principais revistas brasileiras de saúde pública têm uma interface mais próxima das revistas estrangeiras, porém, em geral, o referenciamento se restringe aos respectivos agrupamentos. Os periódicos de saúde pública se agregam na porção superior do gráfico e as revistas antropológicas na parte inferior do mesmo, revelando uma divisão nas revistas brasileiras entre o agregrado de saúde pública e o da antropologia. As revistas estrangeiras em saúde com ênfase social aparecem mais estreitamente relacionadas com as publicações brasileiras.

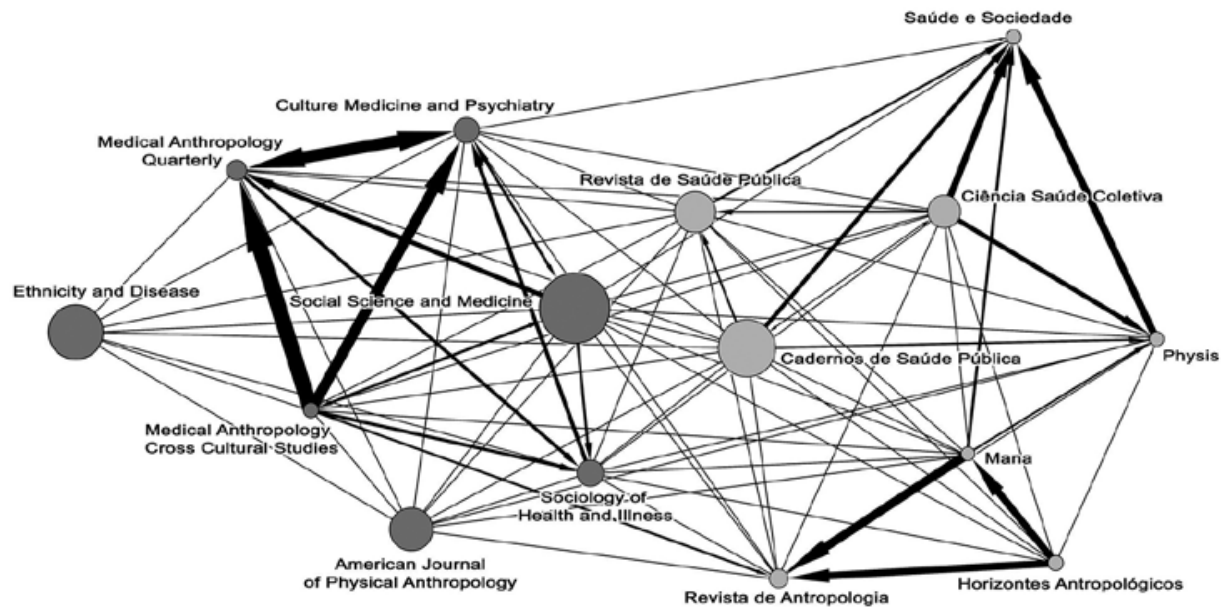

Figura 1: Análise de agrupamento das revistas nacionais e internacionais em saúde e antropologia 
As Tabelas e a Figura apresentadas nos mostram que a visibilidade dos periódicos brasileiros através de indexação e acesso livre está sendo incrementada, mas as revistas de saúde pública têm um histórico melhor e mais longo do que as da área de antropologia. A Figura 1 aponta para um diálogo entre as revistas internacionais da antropologia médica, e revela pouco intercâmbio entre estas e as publicações brasileiras.

Pelo fato de a língua inglesa se manter globalmente como a língua científica predominante, veicular artigos em português continua a ser uma barreira ao diálogo internacional. ${ }^{20}$ Apesar de alguns poucos pesquisadores estrangeiros poderem ler português com facilidade, o espanhol ainda é mais acessível (Becker, 1992:1). No levantamento sobre o número de acessos aos artigos do portal brasileiro da SciELO, cujas publicações são predominantemente em português, Meneghini e Packer (2007) constataram que a maioria dos artigos é acessada nos países em que o idioma oficial é o português ou o espanhol. Desde 2005 foi lançado o portal SciELO Social Sciences, numa parceria entre a SciELO e o Centro Edelstein de Pesquisas Sociais, com apoio da Open Society Institute (OSI), tendo como objetivo disponibilizar versões em inglês de artigos de periódicos latino-americanos de ciências sociais. Atualmente são publicados artigos selecionados de 33 periódicos. $^{21}$

Verificamos o currículo lattes online de 26 antropólogos brasileiros que indicaram saúde como tema de pesquisa para levantar quantos artigos em revistas internacionais eles publicaram entre 2004 e 2008. Detectamos um pequeno aumento de publicações internacionais, em particular naqueles periódicos que publicam em inglês. Entretanto, considerando a prioridade que a Capes e o CNPq atribuem a publicações internacionais, este aumento não parece muito significativo. Como já mencionamos, uma estratégia praticada nos últimos anos tem sido a alternativa de publicar artigos em inglês nos próprios periódicos brasileiros, por exemplo, nos Cadernos de Saúde Pública, na Vibrant e na Ciência e Saúde Coletiva, além da iniciativa mencionada da SciELO Social Science. Contudo, na análise de agrupamentos, essa estratégia não mostrou resultados salientes.

\section{O programa de pesquisa: antropologia e saúde}

O programa de pesquisa em antropologia da saúde tomou a forma de um campo de estudos específico nos anos 1980. No final do século XX ele se consolidou como uma extensa rede de antropólogos com interesses pertinentes e com um corpo razoável de pesquisas e publicações. Em 1998, Minayo havia observado duas vertentes de estudos sobre saúde: uma delas alocada em programas 
de antropologia, identificando-se mais com os paradigmas clássicos e com as discussões fomentadas em departamentos acadêmicos, e a outra, com uma forte orientação interdisciplinar e de colaboração prática, que conta com uma rede de pesquisadores dispersos em programas de graduação em antropologia, de saúde coletiva e outros programas da área biomédica. Minayo descreve esta última vertente como uma nova "interdisciplina”, "adolescente”, com dependência dos paradigmas teórico-conceituais e metodológicos estrangeiros, e ainda hesitante entre a identidade da antropologia médica e da antropologia da saúde.

Nós concluímos que, passados 13 anos desde a avaliação feita por Minayo, a configuração da antropologia da saúde no Brasil representa um programa de pesquisa emergente, com uma matriz disciplinar com certa autonomia em sua articulação com os paradigmas das antropologias médicas do Atlântico Norte, integrado por uma rede de investigadores com perfis de interesse que se articulam com o que definimos acima como um certo ethos e valores predominantes entre os pesquisadores brasileiros.

Roberto Cardoso de Oliveira (1999-2000), em um artigo publicado em inglês sobre a antropologia brasileira, usa os termos "periférica" e "metropolitana" para falar das antropologias mundiais e suas tensões. Assim como Escobar e Ribeiro, ele reconheceu os esforços das antropologias periféricas para alcançarem sua autonomia e um desenvolvimento efetivo em escala global. Cardoso de Oliveira sugere vários indicadores da limitação desses esforços:

1. fragilidade institucional (falta de bibliotecas, de professores concursados com dedicação exclusiva e de recursos financeiros para pesquisa);

2. dependência de países estrangeiros para a formação profissional avançada;

3. mercado de trabalho insuficiente;

4. baixa circulação internacional dos periódicos;

5. foco da pesquisa em território nacional; e

6. um perfil metateórico dependente dos paradigmas eurocêntricos.

Nesta análise mostramos que a antropologia brasileira, juntamente com outros campos acadêmicos no país, está apresentando uma crescente autonomia. O número de programas de pós-graduação tem aumentado a ponto de permitir, nos dias de hoje, que grande parte dos pesquisadores brasileiros conclua uma formação profissional de excelência no próprio país. Isto é particularmente verdadeiro para a antropologia e abrange a antropologia da saúde. Se nos anos 1980 e início dos 1990 o campo foi influenciado por pesquisadores, brasileiros ou estrangeiros, formados no exterior, essa tradição agora se reverteu. Atualmente, as agências de fomento governamentais apoiam menos a realização de cursos de 
doutorado pleno no exterior em favor dos programas de estágio sanduíche, em que o estudante fica em contato com antropologias metropolitanas de quatro a 12 meses durante a sua formação no Brasil.

As pesquisas brasileiras continuam a se concentrar em questões e tópicos de pesquisa de interesse nacional, embora estudos realizados fora do país recebam algum apoio financeiro. Cardoso de Oliveira (1999-2000:21) argumenta que a concentração das pesquisas nas problemáticas nacionais contribuiu, inicialmente, para o desenvolvimento da antropologia brasileira, mas ele encoraja os pesquisadores brasileiros a irem além das fronteiras nacionais. Ribeiro (2006) sugere que as antropologias regionais deveriam estudar as sociedades hegemônicas. No entanto, há pouca evidência de que isto ocorra no campo da antropologia da saúde, pois as pesquisas continuam a ser estimuladas por problemas nacionais e pela oferta de financiamento, com recursos governamentais e internacionais, para assuntos considerados prioritários, tais como violência, AIDS, abuso de drogas, questões de gênero, raça e saúde mental.

O aspecto mais complicado de avaliar é o perfil metateórico, já que envolve tanto o desenvolvimento de paradigmas alternativos no Brasil quanto a circulação internacional destes paradigmas. Gustavo Lins Ribeiro (1999-2000) afirma que a antropologia brasileira se tornou independente em termos da sua produção criativa, mas que no diálogo com as antropologias mundiais a ignorância assimétrica da sua produção se mantém. Esse diálogo assimétrico faz parte da tensão inerente à disseminação do conhecimento, isto é, os centros hegemônicos ignoram o que é produzido em centros não hegemônicos, enquanto estes últimos aceitam os conhecimentos hegemônicos para incorporá-los em sua própria história do conhecimento (Ribeiro, 2006:378). A antropologia brasileira caracteriza-se, de acordo com Ribeiro, por seu cosmopolitismo provinciano, uma vez que para criar seus paradigmas se baseia em paradigmas internacionais, sendo que os modelos subalternos brasileiros circulam menos no cenário antropológico mundial do que o inverso.

As pesquisas antropológicas sobre saúde realizadas nas décadas de 1970 e 1980 se originaram de problemáticas nacionais e suas teorias pouco dialogavam com a antropologia médica do Atlântico Norte. No primeiro Encontro Nacional em Antropologia Médica, em 1993, ficou evidente o alcance e a especificidade das pesquisas em saúde no Brasil. Desde então, a pluralidade de paradigmas se multiplicou, tornando difícil identificar uma unidade no campo da antropologia da saúde. As tendências desenvolvidas pela antropologia da saúde brasileira amadureceram e têm um "discurso de fronteira" que as afasta claramente da antropologia médica do Atlântico Norte. 
Uma abordagem que reflete esse perfil teórico peculiar se manifesta nas discussões a respeito dos conceitos de corpo, pessoa e emoção. Apesar de estas mesmas noções serem usadas também nas antropologias do Atlântico Norte, os debates no Brasil são caracteristicamente permeados pelas problemáticas nacionais e por tendências teóricas distintas. Seeger et al. (1987) propõem um paradigma unificador, fundado no corpo como matriz simbólica, para interpretar as culturas indígenas e suas práticas. O paradigma corporal foi escolhido como uma alternativa aos modelos de parentesco britânicos e norte-americanos, criados para entender as sociedades africanas e que, até então, eram utilizados nos estudos das sociedades ameríndias. As pesquisas etnológicas subsequentes foram fortemente influenciados pelo paradigma do corpo como matriz simbólica da sociedade, incluindo aqueles estudos sobre as práticas e os cuidados de saúde indígenas. Além da etnologia, a noção de pessoa como uma construção social e moral se consolidou como foco central para o estudo dos grupos sociais em sociedades complexas. O estudo clássico de Duarte sobre os nervos (1986) marca a introdução do tema nos estudos sobre saúde. A partir de então, este se tornou um paradigma central nos estudos antropológicos brasileiros de saúde.

Embora as noções de corpo sejam um paradigma presente na maioria das antropologias desde os anos 1980, os debates no Brasil têm bastante afinidade com a antropologia clássica francesa, com as obras de Durkheim, Mauss, Dumont, mas também Foucault (Duarte, 2003; Minayo, 1998; Leibing, 2007), e menos com a abordagem reconhecida como "biocultural", da antropologia médica do Atlântico Norte. Duarte sugere o termo "perturbação físico-moral” no lugar de disease, illness e sickness, conceitos utilizados na antropologia médica, com o intuito de enfatizar o caráter social e moral da construção da doença. Ao salientar a construção social do corpo e a natureza relacional da saúde, ele argumenta que a compreensão antropológica dos processos de saúde e doença não pode ser separada das preocupações e dos paradigmas desenvolvidos no âmbito da antropologia de modo geral.

Em vários artigos, Duarte e outros autores contestam o que eles chamam de "antropologia médica norte-americana hegemônica". Em sua revisão da pesquisa sobre os nervos, Duarte (1993) se opõe aos antropólogos norte-americanos que veriam o corpo, em última análise, como substrato natural das doenças (illness). A desconstrução da esfera biológica é evidente em muitos trabalhos brasileiros (Rohden, 2001). Defendendo um "culturalismo radical", no qual o corpo não deve ser visto como um organismo natural determinante, mas como a fase ativa da experiência e das relações, Duarte (1998a, 1998b) coloca os estudos antropológicos sobre saúde no eixo disciplinar e se posiciona contra o desenvolvimento 
de uma subespecialidade que considera o corpo como um objeto do determinismo biológico. Para ele e outros antropólogos brasileiros, o campo da antropologia médica característico da América do Norte limita-se a círculos cada vez menores de diálogo e está se fechando em si mesmo epistemologicamente (Duarte 1998a e 1998b). Além disso, os pesquisadores brasileiros tendem a rejeitar os métodos desenvolvidos pela antropologia médica, particularmente os procedimentos de avaliação rápida, dizendo que esse método, além de ser uma simplificação rasa dos conceitos, reduz a antropologia a um uso meramente instrumental (Menéndez, 1998; Minayo et al. 2003).

Um exemplo dessa rejeição à abordagem norte-americana é a ausência de uma versão em português do livro Death without Weeping: The Violence of Everyday Life in Brazil, resultado da pesquisa de Nancy Scheper-Hughes no Brasil. O livro, publicado em 1992, foi bem recebido nos meios acadêmicos da América do Norte e Europa, sendo aclamado como uma etnografia magistral sobre a pobreza. Aqui, no entanto, esse trabalho foi recebido com críticas e o livro inspirou resenhas negativas. Vários pesquisadores afirmam que o argumento de ScheperHughes sobre a negligência seletiva se apoia em um modelo biológico determinista das emoções (Duarte, 1993; Franch \& Lago-Falcão, 2004; Santos, 1995). Outros criticaram seus métodos de seleção de dados e a ausência de citações às pesquisas brasileiras mais relevantes sobre o tema (Sigaud, 1995; Scott, 2004). O trabalho de Duarte é citado em sua bibliografia, mas ele não é mencionado no texto, nem mesmo quando a autora discute brevemente a noção de pessoa versus individualismo (1992:414).

Lygia Sigaud (1995), outra antropóloga brasileira que faz uma avaliação crítica do livro, atribui o horror, a indignação e a ênfase na escassez expressados no trabalho de Scheper-Hughes ao olhar que prevalece em um país dominante. Ela e outros argumentam que as perguntas feitas aqui sobre os problemas sociais e econômicos do país não são as mesmas da antropologia médica crítica, porque no Brasil os antropólogos estão mais envolvidos com questões de interesse geral da população e com as políticas públicas de saúde (Minayo, 1998:43). Essa diferença de olhar se reflete também no diálogo interdisciplinar entre a saúde coletiva e a antropologia.

Os debates na América Latina entre as ciências sociais e a medicina, no âmbito da medicina social, medicina preventiva, epidemiologia social e saúde coletiva, são consistentes em sua crítica ao modelo ecológico e da história natural das doenças (Nunes, 1985). Originalmente baseado em uma perspectiva marxista estrutural e generalizante, hoje há um diálogo criativo entre os acadêmicos de vários países da América Latina, articulando antropologia e epidemiologia na 
tentativa de compreender as práticas de saúde e a dinâmica micropolítica da vida diária (Garnelo \& Langdon, 2005). O mesmo se observa na rede de pesquisadores brasileiros e latino-americanos reunidos pelo movimento da saúde coletiva (Briceño-León, 1999; Briceño-León et al., 2000; Minayo \& Coimbra, 2005; Nunes, 2003, 2006).

Desde 1980, a antropologia brasileira vem contribuindo para esse diálogo, assinalando o contraste entre as epistemologias quantitativa e qualitativa que separam as duas disciplinas e avaliando o êxito da relação crescente entre elas (Canesqui, 2008; Coimbra, 2000; Minayo et al., 2003; Loyola, 2008). Mesmo entre aqueles epidemiologistas mais ligados à abordagem biológica, nota-se que suas discussões e pesquisas explicitam uma relação com os conhecimentos antropológicos e, apesar de continuarem a sublinhar a importância dos métodos qualitativos em saúde, têm também desenvolvido metodologias mistas unindo técnicas quantitativas e qualitativas nas pesquisas que estão produzindo (Minayo, et al. 2006). No entanto, existe uma visão predominante na área de que o conhecimento antropológico não deve estar a serviço da medicina ou ser subserviente às práticas biomédicas.

\section{Conclusão}

Nesta apresentação argumentamos a favor da emergência daquilo que Arturo Escobar chamou de um programa de pesquisa. No campo da saúde, ele se caracteriza por uma pluralidade de perspectivas que circulam em torno de questões antropológicas ligadas a processos de saúde e doença, estando também associadas aos aspectos sociais e políticos particulares do Brasil. O programa de pesquisa tem natureza interdisciplinar e está em diálogo predominantemente com a saúde coletiva. Diferente das antropologias do Atlântico Norte, o discurso antropológico brasileiro sobre saúde insiste nas forças culturais e sociais como fatores determinantes das práticas e das representações nesse campo. O programa de pesquisa da antropologia da saúde no Brasil não nega os conhecimentos biológicos, porém concebe o corpo e as doenças como aspectos construídos relacionalmente. A despeito da pluralidade, da experimentação de novos paradigmas metodológicos e de arranjos possíveis entre dados quantitativos e qualitativos, o programa de pesquisa mantém uma dimensão epistemológica unificadora que é orientada para as esferas social, cultural e política.

As questões que apontamos sobre a forma como a antropologia brasileira aborda o corpo e a forma como este paradigma é contrastado com as noções sobre corpo que circulam na antropologia médica do Atlântico Norte trazem uma dimensão subjacente importante da perspectiva metateórica e do ethos 
interpretativo do programa de pesquisa em antropologia da saúde. Essa dimensão torna-se claramente visível em publicações e eventos sobre saúde na antropologia, em ciências sociais e saúde coletiva que ocorrem em toda a América Latina, em debates travados em espanhol e português.

Diversos fatores podem estar pesando para essa pouca inserção internacional e mesmo para a marginalização dos estudos antropológicos brasileiros em saúde, sobretudo em relação à Europa e aos Estados Unidos, como demonstram as análises cienciométricas e infométricas que aplicamos ao campo da saúde. As limitadas referências a autores brasileiros, como também a pequena circulação de revistas na comunidade mundial de antropológos médicos indicam que a antropologia da saúde ao estilo brasileiro não é totalmente reconhecida pelas antropologias médicas, ou da saúde, da América do Norte e da Europa. Entre esses fatores, podemos citar o fato de que a maior parte das publicações de estudiosos brasileiros é feita em língua portuguesa, mantendo a produção brasileira desconhecida de uma comunidade científica internacional cuja língua comum é o inglês. Há ainda outros fatores, ligados à dinâmica da relação entre as chamadas antropologias "centrais" e "periféricas", e a forma como o conhecimento circula no âmbito internacional.

Uma constatação possível é a de que não basta o crescimento quantitativo, como prevê um certo protocolo produtivista em vigor atualmente na academia brasileira - mas não só nesta - para que as pesquisas feitas no Brasil tenham um impacto importante nas antropologias mundiais. Questões como em que medida os estudos antropológicos de saúde realizados no Brasil têm provocado mudanças ou trazido novas discussões para as antropologias da saúde no plano internacional, e mesmo até que ponto a antropologia da saúde tem proporcionado novos paradigmas para a antropologia de modo geral empurram o debate sobre a importância do campo e desse programa de pesquisa para muito além dos índices de produção.

Isso pode trazer elementos para o questionamento das diretivas atuais no campo científico e acadêmico brasileiro de medir o impacto dessa produção científica a partir de índices quantitativos, deixando em segundo plano a análise da qualidade e do efetivo impacto, tanto científico quanto social e político, dessa produção. Os dados analisados neste artigo mostram que uma produção abundante numericamente, seja em termos de publicações, seja de teses e dissertações defendidas, não garante a circulação, o impacto e mesmo o sucesso de um programa de pesquisa. Pensar em novos paradigmas para a avaliação da produção científica no campo das ciências humanas de modo geral, e dos estudos antropológicos de saúde especificamente implica refletir também sobre o 
perfil desse programa que hoje temos em via de consolidação, mas ainda com um grande caminho a percorrer no interior do campo antropológico nacional e internacional.

$$
* * *
$$

As autoras agradecem à Sociedade Real de Artes e Ciências de Göteborg (Kungliga Vetenskaps-och Vitterhetssamhället) pelo suporte financeiro para a pesquisa de campo feita no Brasil por Maj-Lis Follér, realizada entre fevereiro e março de 2008; ao Jubileumsfonden da Universidade de Gothenburg por financiar a visita de seguimento em abril de 2008; e ao CNPq, que vem apoiando Esther Jean Langdon e Sônia Weidner Maluf como pesquisadoras a ele vinculadas. Agradecemos também a Carlos E. Coimbra Jr pelo apoio para as viagens durante a elaboração deste artigo, e à Nádia Heusi Silveira pela tradução de partes do artigo.

Recebido em 19/06/2012

Aceito em 31/06/2012

Esther Jean Langdon é professora titular na Universidade Federal de Santa Catarina e pesquisadora 1B no CNPq. Mora no Brasil desde 1983, onde tem estudado as políticas de saúde indígena, antropologia da saúde, narrativas, performance e xamanismo.

Maj-Lis Follér é doutora em ecologia humana e professora associada na Universidade de Gothenburg, na Suécia. Realizou pesquisas de campo no Brasil e no Peru. Atualmente estuda AIDS e sociedade civil em Moçambique. Recentemente editou "Brazil: Politics of Exclusion and Inclusion" em Anales - Nueva Época No. 13.

Sonia Weidner Maluf é professora associada do Departamento de Antropologia da Universidade Federal de Santa Catarina. Pesquisa sobre antropologia do sujeito; pessoa, corpo e saúde; gênero e teoria feminista; políticas públicas; religiosidades contemporâneas. É pesquisadora do CNPq. 


\section{Notas}

1. O conceito de "pensamento de fronteira" foi desenvolvido por Walter Mignolo como "[...] o momento em que se fratura o imaginário do sistema-mundo" (2000:23).

2. O objetivo desta seção é fornecer alguns elementos da formação do campo. Não pretendemos, no entanto, traçar uma história das pesquisas em saúde ou de como o tema da saúde entrou nas pesquisas antropológicas no Brasil.

3. Para Pereira de Queiroz (1983), Bastide, inicialmente influenciado em sua análise das religiões afro-brasileiras por Nina Rodrigues e Euclides da Cunha, de um lado, e por Lévy-Bruhl, de outro, foi gradualmente abandonando as ideias de Lévy-Bruhl sobre o pensamento primitivo, assumindo a noção de "sistemas mitológicos diferentes".

4. Em contraste com o que identifica Nunes quanto às relações entre ciências sociais e saúde e ao que chama de "marcas claras da influência norte-americana" até os anos 60 (Nunes, 1992:64). Ele se refere sobretudo às missões de pesquisa e às pesquisas articuladas com políticas de saúde (entre as quais estão as de Charles Wagley na Amazônia, nos anos 40, e a do antropólogo Kalevo Oberg, nos anos 50). Nunes também evidencia um deslocamento das leituras e dos diálogos com os países do norte em relação às ciências sociais da saúde, tendo os autores franceses passado a predominar a partir dos anos 70 (:66).

5. Há três antropólogos norte-americanos com livros traduzidos para o português: Csordas (2008), Greenfield (1999) e Nations (2009). O livro de Helman, Culture, Health and Illness (2009), foi traduzido pela primeira vez em 1984. Apesar de seu trabalho ser bem aceito por profissionais de saúde, a maioria dos antropólogos brasileiros o rejeita, pois o livro promove um uso instrumental da antropologia.

6. Ele traduziu um artigo clássico de Young (1976) para seus alunos e planejou publicar uma coleção de artigos traduzidos sobre antropologia médica.

7. Defendida em 1985 e orientada por Gilberto Velho.

8. Revisões anteriores incluem Queiroz (1980), Oliveira (1984) e Ibáñez-Novión (1983).

9. Retornaremos aos trabalhos de Duarte na segunda parte deste artigo.

10. Diana Brown, como professora visitante na UNICAMP, ofereceu a disciplina “antropologia médica” em 1979, e teve entre seus alunos Queiroz (1980), Cardoso (1999) e Oliveira (1984).

11. Resenhas sobre antropologia da saúde no Brasil (Diniz, 1997; Carrara, 1994; Leibing, 2007) caracterizam os estudos em saúde indígena como focados nas medicinas locais ou na etnomedicina, e não levam em consideração que os pesquisadores que se debruçam sobre este tema têm o interesse comum de entender as transformações das práticas de saúde e os efeitos das políticas públicas, tópicos fundamentais para o desenvolvimento do programa de pesquisa como um todo (Langdon \& Garnelo, 2004). 
12. Canesqui (2003) fala da "forte expansão e amadurecimento do campo" nessa década $(: 110)$

13. Consolidando-se, no entanto, nas áreas de saúde coletiva e saúde pública e social, diversas publicações interdisciplinares, como Saúde e Sociedade, História ciência e saúde Manguinhos, Ciência e Saúde Coletiva, Physis, nas quais muitos antropólogos que pesquisam na área de saúde publicam.

14. Um exemplo são os encontros da Abrasco (Associação Brasileira de Saúde Coletiva).

15. Vibrant, Brazilian Virtual Anthropology, revista eletrônica publicada pela ABA desde 2004 aceita artigos em ingles, francês e espanhol na tentativa de dialogar com as antropologias não lusófonas.

16. A pesquisa bibliométrica foi efetuada na biblioteca universitária da Universidade de Gothenburg, por Håkan Carlsson, auxiliado por Anna Svensson.

17. Apesar de não ser um indexador de periódicos científicos, a SciELO acaba sendo utilizada como tal na avaliação e no reconhecimento dos periódicos brasileiros e, em menor medida, dos latino-americanos.

18. A análise de agrupamentos (cluster analysis) é uma técnica estatística baseada na organização ou na classificação do material ou da amostra em vários agrupamentos similares entre si ou mais homogêneos que o todo, de acordo com critérios definidos pelo analista.

19. Informações disponíveis em http://www.scopus.com

20. O que não quer dizer que a barreira linguística seja o único fator desse baixo intercâmbio, como veremos. Outros fatores não discutidos de forma detalhada no âmbito deste artigo pesam na relação assimétrica entre as antropologias mundiais.

21. Estes, no entanto, não entraram como corpus para a análise neste artigo. 


\section{Referências bibliográficas}

ALVES, Paulo Cesar. 1993. “A Experiência da Enfermidade: Considerações Teóricas”. Cadernos de Saúde Pública, 9 (3):263-271.

ALVES, Paulo Cesar. 2006. "Fenomenologia e as Abordagens Sistêmicas nos Estudos Socioantropológicos da Doença”. Cadernos de Saúde Pública, 22 (8):1547-1554.

ALVES, Paulo Cesar \& MINAYO, Maria Cecilia de Souza (orgs.). 1994. Saúde e Doença: Um Olhar Antropológico. Rio de Janeiro: Editora Fiocruz.

ALVES, Paulo Cesar \& RABELO, Miriam Cristina. 1997. "Being a Nervous Person: Narratives and the Construction of a Self”. In: Annette Leibing (org.). The Medical Anthropologies in Brazil. Special Volume. Curare, 12:9-21. Berlin: VWB - Verlag für Wissenschaft und Bildung.

. 1998. “O Status Atual das Ciências Sociais em Saúde no Brasil: Tendências”. In: Paulo Cesar Alves \& Miriam Cristina Rabelo (orgs.). Antropologia da Saúde, Traçando Identidade e Explorando Fronteiras. Rio de Janeiro: Relume Dumaré. pp. 13-29.

ARAúJO, A. M. 1977. Medicina Rústica. São Paulo: Companhia Editora Nacional.

ARRUTI, José M. 1997. “Uma antropologia Mameluca a partir de Darcy Ribeiro, 1995:

O Povo Brasileiro...”. Revista da Faculdade de Letras, 21 (1):301-312.

BASTIDE, Roger. 1967 [1965]. Sociologia das doenças mentais. São Paulo: Companhia Editora Nacional,

BECKER, Howard. 1992. "Social Theory in Brazil”. Sociological Theory, 10 (1):1-5.

BERTOLLI FILHO, Claudio. 2003. "A sociologia de Gilberto Freyre e a educação para a saúde”. Ciência \&Educação, 9 (1):105-121.

BRICEÑO-LEÓN, R. (org.). 1999. Ciencias sociales y salud en América Latina: un balance. Caracas: Editorial Ex libris/Fundación Polar.

BRICEÑO-LEÓN, Roberto; MINAYO, Maria Cecília de Souza \& COIMBRA Jr., Carlos E. A. (orgs.). 2000. Salud y equidad: Una mirada desde las ciencias sociales. Rio de Janeiro: Editora Fiocruz.

BUCHILlET, Dominique (org.). 1991a. Medicinas Tradicionais e Medicina Ocidental na Amazônia. Belém: MPEG/CEJUP/UEP. 
1991b. "A Antropologia da Doença e os Sistemas Oficiais de Saúde”. In: Dominique Buchillet (org.). Medicinas Tradicionais e Medicina Ocidental na Amazônia. Belém: MPEG/CEJUP/UEP. pp. 21-44.

CABRAL, Oswaldo Rodrigues. 1942. Médicos e Charlatões do Passado. Florianópolis: Imprensa Oficial.

CAMARGO Jr., Kenneth Rocha. 2005. "As Ciências Sociais e Humanas e a Saúde Coletiva”. Physis, Revista de Saúde Coletiva, 15 (2):191-192.

CANESQUI, Ana Maria. 2008. "As Ciências Sociais e Humanas em Saúde na Associação Brasileira de Pós-graduação em Saúde Coletiva”. Physis, Revista de Saúde Coletiva, 18 (2):215-250.

(org.). 1995. Dilemas e Desafios das Ciências Sociais na Saúde Coletiva. São Paulo: Hucitec-Abrasco.

CARDOSO DE OLIVEIRA, Luis Roberto. 2008. "Dialogical and Power Differences in World Anthropologies. Dossier 'Antropologia Sul-Sul'”. Vibrant, 5 (2):268-276. Disponível em: http://www.vibrant.org.br/portugues/artigosv5n2.htm. Acesso em: 15/08/2012.

CARDOSO DE OLIVEIRA, Roberto. 1999-2000. "Peripheral Anthropologies 'versus' Central Anthropologies. Epistemological Dimensions”. Journal of Latin American Anthropology, 4 (2):10-30.

CARDOSO, Marina. 1999. Médicos e Clientela da Assistência Psiquiátrica à Comunidade. São Paulo: UFSCar

CARRARA, Sergio. 1994. "Entre Cientistas e Bruxos: Dilemas e Perspectivas da Análise Antropológica da Doença”. In: Paulo Cesar Alves \& Maria Cecília de Souza Minayo (orgs.). Saúde e Doença: Um Olhar Antropológico. Rio de Janeiro: Editora Fiocruz. pp. 33-45.

CASCUDO, Luis da Câmara. 1971. Tradição Ciência do Povo. São Paulo: Perspectiva.

COIMBRA Jr., Carlos E. A. (org). 1991. "Saúde de Populações Indígenas”. Cadernos de Saúde Pública, VII (4). Número Temático.

. 2000. "Comment on: Integração entre Epidemiologia e Antropologia, by A.M.J. Gadelha”. História, Ciências, Saúde, VI (3):689-704.

CSORDAS, Thomas. 2008. Corpo/Significado/Cura. Porto Alegre: Editora UFRGS.

DINIZ, Deborah. 1997. “O que é isso que chamamos Antropologia da Saúde no Brasil?”. Pós: Revista Brasiliense de Pós-Graduação em Ciências Sociais, 1 (1):213-234.

DUARTE, Luis Fernando Dias. 1986. Da Vida Nervosa nas Classes Trabalhadoras Urbanas. Rio de Janeiro: Jorge Zahar Editor/CNPq. 
1993. “Os Nervos e a Antropologia Médica Norte-Americana: Uma Revisão Crítica”. Physis, Revista de Saúde Coletiva, 3 (2):43-73.

. 1997. "Nerves and Nervousness in Brasilian Urban Culture”. In: Anette Leibing (ed.). The Medical Anthropologies in Brazil. Special Volume. Curare, 12:21-38; Berlin: Verlag für Wissenschaft und Bilding

1998a. "Pessoa e Dor no Ocidente”. Horizontes Antropológicos, 9:13-29.

. 1998b. "Introdução". In: Luis Fernando Dias Duarte \& Ondina Fachel Leal (orgs.). Doença, Sofrimento, Perturbação: Perspectivas Etnográficas. Rio de Janeiro: Editora Fiocruz. pp. 1-27.

. 1999-2000. "Person and Psychologization in Brazil: a Study in Moral Regulation”. Journal of Latin American Anthropology, 4 (2) / 5 (1):142-171.

2003. "Indivíduo e Pessoa na Experiência da Saúde e da Doença”. Ciência e Saúde Coletiva, 8 (1):173-181.

ESCOBAR, Arturo. 2004. “The Latin American Modernity/Coloniality Research Program: Worlds and Knowledges Otherwise”. Cuadernos del CEDLA, 16:31-67.

2005. Mas allá del tercer mundo. Globalización y diferencia. Bogotá: ICAN.

FER NANDES, Florestan. 1961. Folclore e Mudança Social em São Paulo. São Paulo: Anhembi.

FIGUEIRA, Sérvulo A. 1981. O Contexto Social da Psicanálise. Rio de Janeiro: Ed. Francisco Alves.

(org.). 1985. Cultura da Psicanálise. São Paulo: Editora Brasiliense.

FRANCH, Mônica \& LAGO-FALCÃO, Tânia. 2004. "Será que Elas Sofrem? Algumas Observações sobre Death without Weeping de Nancy Scheper-Hughes”. Política \& Trabalho. Revista de Ciências Sociais, 20:181-196.

GALVÃO, Eduardo. 1951. "Panema: Uma Crença do Caboclo Amazônico”. Revista do Museu Paulista, 5:221-225.

1952. The Religion of an Amazon Community. Ph.D. dissertation, Columbia University.

GARNELO, Luiza Perreira. 2003. Poder, Hierarquia e Reciprocidade: Saúde e Harmonia entre os Baniwa do Alto Rio Negro. Rio de Janeiro: Editora Fiocruz.

GARNELO, Luiza Perreira \& LANGDON, Jean. 2005. "A Antropologia e a Reformulação das Práticas Sanitárias na Atenção Básica à Saúde”. In: Maria Cecília de Souza Minayo \& Carlos E.A. Coimbra Jr. (orgs.). Críticas e Atuantes: Ciências Sociais e Humanas em Saúde na América Latina. Rio de Janeiro: Editora Fiocruz. pp. 136-156. 
Geertz, Clifford. 1973. "Ethos, World View and the Analysis of Sacred Symbols". In: Interpretation of Cultures. New York: Basic Books. pp.126-141.

GIBBS, W. Wayt. 1995. "Lost Science in the Third World”. Scientific American, 273 (2): 92-99.

GOLDENBERG, Paulete; MARSIGLIA, Regina Maria Giffoni \& GOMES, Mara Helena de Andréa (orgs.). 2003. O Clássico e o Novo. Rio de Janeiro: Editora Fiocruz.

GREENFIELD, Sidney M. 1999. Cirugias do Além: Pesquisas Antropológicas sobre Curas Espirituais. Petrópolis: Editora Vozes.

GROISMAN, Alberto (org.). 2005. “Saúde, Religião e Corpo”. Seção Temática. Ilha, Revista de Antropologia, 7 (1-2):111-162.

HELMAN, Cecil. 2009. Cultura, Saúde e Doença. 5. ed. Porto Alegre: Artes Médicas.

IBÁÑEZ-NOVIÓN, Martin Alberto; IBÁÑEZ-NOVIÓN, Olga C. Lopez de \& SERRA, Ordep José Trindade. 1978. "O Anatomista Popular: Um Estudo de Caso". Anuário Antropológico, 77:87-107. Rio de Janeiro: Tempo Brasileiro.

1983. "Prefácio: Antropologia e Medicina: Algumas Considerações”. In: Martin Alberto Ibáñez-Novión \& Ari M. Teixeira Ott (orgs.). Adaptação à Enfermidade e sua Distribuição entre Grupos Indígenas da Bacia Amazônica. Caderno CEPAM n. l. Belém: Museu Goeldi/CNPq. pp.9-36.

IBÁÑEZ-NOVIÓN, Martin Alberto \& OTT, Ari M. Teixeira (orgs.). 1983. Adaptação à Enfermidade e sua Distribuição entre Grupos Indígenas da Bacia Amazónica. Caderno CEPAM n. l. Belém: Museu Goeldi/CNPq.

KNAUTH, Daniela \& VÍCTORA, Ceres G. (orgs.). 2002. “Sexuality and AIDS”. Número Especial. Horizontes Antropológicos, 17.

LANGDON, Esther Jean \& GARNELO, Luiza Perreira (orgs.). 2004. Sáude dos Povos Indígenas: Reflexões Sobre Antropologia Participativa. Rio de Janeiro: Contra Capa Livraria/ ABA.

LEAL, Ondina Fachel (org.). 1995. Corpo e Significado. Ensaios de Antropologia Social. Porto Alegre: Editora da Universidade/UFRGS.

(org.). 1998. Corpo, Doença e Saúde. Número Especial. Horizontes Antropológicos, 9.

LEIBING, Annette. 2007. "Much More than Medical Anthropology: The Healthy Body and Brazilian Identity”. In: Francine Saillant \& Serge Genest (eds.). Medical Anthropology. Regional Perspectives and Shared Concerns. Oxford: Blackwell Publishing. pp. 58-70. 
LOYOLA, Maria Andréa. 1984. Médicos e Curandeiros. Conflito Social e Saúde. São Paulo: DIFEL.

2008. “A Saga das Ciências Sociais na Área da Saúde Coletiva: Elementos para Reflexão". Physis, Revista de Saúde Coletiva, 18 (2):251-275.

MEGGERS, Betty. 1968. "Foreword". In: Darcy Ribeiro. The Civilizational Process. Washington, D.C.: Smithsonian Institute. pp. v-x.

MENEGHINI, Rogerio. 2007. "Editorial, The Internationalization of Cadernos de Saúde Pública”. Cadernos de Saúde Pública, 23 (10):2260.

MENEGHINI, Rogerio \& PACKER, Abel L. 2007. "Is there Science beyond English?". EMBO Reports, 8 (2):112-116.

MENÉNDEZ, Eduardo. 1998. “Antropologia Médica e Epidemiologia: Processo de Convergência ou Processo de Medicalização?”. In: Paulo Cesar Alves \& Miriam Cristina Rabelo (orgs.). Antropologia da Saúde: Traçando Identidade e Explorando Fronteiras. Rio de Janeiro: Fiocruz/Relume Dumará. pp. 71-95.

MIGNOLO, Walter D. 2000. Local Histories/Global Designs: Coloniality, Subaltern Knowledges, and Border Thinking. Princeton, N.J.: Princeton University Press.

MINAYO, Maria Cecília de Souza. 1998. "Construção da Identidade da Antropologia na Área de Saúde: O Caso Brasileiro”. In: Paulo Cesar Alves \& Miriam Cristina Rabelo (orgs.). Antropologia da Saúde: Traçando Identidade e Explorando Fronteiras. Rio de Janeiro: Relume Dumará. pp. 29-47.

MINAYO, Maria Cecília de Souza \& COIMBRA Jr., Carlos E. A. (orgs.). 1993. “Abordagens Antropológicas em Saúde”. Número Temático. Cadernos de Saúde Pública, 9 (3).

(orgs.). 2005. Críticas e Atuantes: Ciências Sociais e Humanas em Saúde na América Latina. Rio de Janeiro: Editora Fiocruz.

MINAYO, Maria Cecília de Souza; ASSIS, Simone Gonçalvez de \& SOUZA, Edinilsa Ramos de (orgs.). 2006. Avaliação por Triangulação de Métodos: Abordagens de Programas Sociais. Rio de Janeiro: Editora Fiocruz.

MINAYO, Maria Cecília de Souza; ASSIS, Simone Gonçalvez de; DESLANDES, Suely Ferreira \& SOUZA, Edinilsa Ramos de. 2003. "Possibilidades e Dificuldades nas Relações entre Ciências Sociais e Epidemiologia”. Ciência e Saúde Coletiva, 8 (1):97-107.

MUSSOLINI, Gioconda. 1946. “Os Meios de Defesa contra a Moléstia e a Morte em Duas Tribos Brasileiras: Kaingang de Duque de Caxias e Bororo Oriental”. Revista do Arquivo Municipal, 110:7-152. 
. 1949. "Notas sobre os Conceitos de Moléstia, Cura e Morte entre os índios Vapidiana”. Sociologia, VI (2):135-155.

NATIONS, Marilyn. 2009. Corte a Mortalha: O Cáculo Humano da Morte Infantil no Ceará. Rio de Janeiro: Editora Fiocruz.

NUNES, Everardo Duarte. 1985. As Ciências Sociais em Saúde na América Latina. Tendências e Perspectivas. Brasilía: OPAS.

1992. "As Ciências Sociais em Saúde: reflexões sobre as origens e a construção de um campo de conhecimento". Saúde e Sociedade, 1 (1):59-84.

2003. “Ciências Sociais e Saúde”. Ciência \& Saúde Coletiva, 8 (1):4-7.

. 2006. “A Trajetória das Ciências Sociais em Saúde na América Latina: Revisão da Produção Científica”. Revista de Saúde Pública, 40:64-72.

OLIVEIRA, Elda Rizzo de. 1984. O que é Medicina Popular. São Paulo: Brasiliense.

OVERING, Joana. 1989. "The Aesthetics of Production: The Sense of Community among the Cubeo and Piaroa". Dialectical Anthropology, 14:159-75.

. 2003. "In Praise of the Everyday: Trust and the Art of Social Living in an Amazonian Community”. Ethnos, 68 (3):29-317.

PEIRANO, Mariza. 2005. "A Guide to Anthropology in Brazil”. Vibrant, 2 (1-2):54-87. Disponível em: http://www.vibrant.org.br. Acesso em:09/ 09 /2012.

QUEIROZ, Marcos de Souza. 1980. “Estudos sobre Medicina Popular no Brasil”. Religião e Sociedade, 5:241-250

. 1982. The Social Construction of Health and Illness in Iguape. Brazil. Ph.D. Dissertation, University of Manchester.

QUEIROZ, Marcos de Souza \& CANESQUI, Ana Maria. 1986a. "Contribuições da Antropologia à Medicina: Uma revisão de Estudos no Brasil”. Revista Saúde Pública, 20 (2):14l-15l.

1986b. "Antropologia da Medicina: Uma Revisão Teórica”. Revista de Saúde Pública, 20 (2):152-164.

QUEIROZ, Maria Isaura Pereira de. 1983. "Nostalgia do outro e do alhures. A obra sociológica de Roger Bastide". In: . Roger Bastide: sociologia. São Paulo: Ed. Ática.

RABELO, Miriam Cristina; ALVES, Paulo Cesar \& SOUZA, Iara Maria (orgs.). 1999. Experiência de Doença e Narrativa. Rio de Janeiro: Editora Fiocruz. 
RAMOS, Arthur. 1934. O Negro Brasileiro: Etnografia Religiosa e Psicanálise. Rio de Janeiro: Civilização Brasileira.

RESTREPO, Eduardo \& ESCOBAR, Arturo. 2005. "Other Anthropologies and Anthropology Otherwise: Steps to a World Anthropology Network". Critique of Anthropology, 25 (2):99-128.

RIBEIRO, Adelia Miglievich. 2011. "Darcy Ribeiro e o enigma Brasil: um exercício de descolonização epistemológica”. Sociedade e Estado, 26 (2):23-49. Disponível em: http:// dx.doi.org/10.1590/S0102-699220110002000. Acesso em: 24/09/2012.

RIBEIRO, Darcy. 1956. "Convívio e Contaminação. Efeitos Dissociativos da Depopulação Provocada por Epidemias em Grupos Indígenas”. Sociologia, São Paulo, 18:3-50.

1968. The Civilizational Process. Washington, D.C.: Smithsonian Institute.

1970. Os Índios e a Civilização: A Integração das Populações Indígenas no

Brasil Moderno. Rio de Janeiro: Editora Civilização Brasileira.

RIBEIRO, Gustavo Lins. 1999-2000. "Introduction: Reading Brazilian Anthropologists”. Journal of Latin American Anthropology, 4 (2) / 5(1):4-10.

. 2006. "World Anthropologies. Cosmopolitics for a New Global Scenario in Anthropology”. Critique of Anthropology, 26 (4):363-386.

RIBEIRO, Gustavo Lins \& ESCOBAR, Arturo (eds.). 2006. World Anthropologies: Disciplinary Transformations within Systems of Power. New York: Berg.

RODRIGUES, José Carlos. 1975. Tabu do Corpo. Rio de Janeiro: Achiamé.

ROHDEN, Fabíola. 2001. Uma Ciência da Diferença: Sexo e Gênero na Medicina da Mulher. Rio de Janeiro: Editora Fiocruz.

SANTOS, Ricardo Ventura. 1995. "Review of Death without Weeping: The Violence of Everyday Life”. American Journal of Human Biology, 7 (1):100-101.

SANTOS, Ricardo Ventura \& COIMBRA Jr., Carlos E. A. (orgs.). 1994. Saúde e Povos Indígenas. Rio de Janeiro: Editora Fiocruz.

SCHEPER-HUGHES, Nancy. 1992. Death without Weeping. The violence of everyday life in Brazil. Berkeley: University of California Press.

SCOTT, Russel Parry. 2004. "Anthropologias Nacionais e Articulações Internacionais: Brasil e Estados Unidos”. In: Marcos Guedes de Oliveira (org.). Brasil e EUA no Novo Milênio. Recife: NEA/Ed. Universitária da UFPE. pp. 101-126. 
1986. Sistemas de Cura: As Alternativas do Povo. Mestrado em Antropologia, Universidade Federal de Pernambuco.

SEEGER, Anthony; DAMATTA, Roberto \& VIVEIROS DE CASTRO, Eduardo. 1987 [1979]. "A Construção da Pessoa nas Sociedades Indígenas Brasileiras". In: João Pacheco de Oliveira Filho (org.). Sociedades Indígenas e Indigenismo no Brasil. Rio de Janeiro: UFRJ/ Editora Marco Zero. pp. 11-30.

SIGAUD, Lygia M. 1995. "Fome e Comportamentos Sociais: Problemas de Explicação em Antropologia”. Mana, 1 (1):167-175.

VELHO, Gilberto \& FIGUEIRA, Sérvulo (orgs.). 1981. Família, Psicologia e Sociedade. Rio de Janeiro: Campus.

VERANI, Cibele \& MORGADO, Anástacio. 1991. "Fatores Culturais Associados à Doença de Reclusão”. In: Carlos E. Coimbra Jr. (org.). Saúde de Populações Indígenas. Número Temático. Cadernos de Saúde Pública, VII (4):515-538.

VÍCTORA, Ceres; KNAUTH, Daniela Ríva \& TERTO Jr., Veriano (orgs.). 2006. Direitos Sexuais. Numero temático. Horizontes Antropológicos, 26.

VIRTUAL HEALTH LIBRARY. 2008. "The indexing evolution of Latin American and Caribbean Journals". Newsletter. BIREME/OPS/OMS, 17/12/2008. Disponível em: http://espacio.bvsalud.org/boletim.php?articleld=12171754200833. Acesso em:15/01/2010

WAGLEY, Charles. 1964 [1953]. Amazon Town: A Study of Man in the Tropics. New York: Alfred A. Knopf.

WOORTMANN, Klaas. 1977. "Hábitos e Ideologias Alimentares em Grupos Sociais de Baixa Renda. Relatório Final”. Série Antropologia 20. Brasília: Departamento de Antropologia, Universidade de Brasília.

YOUNG, Allan. 1976. "Some Implications of Medical Beliefs and Practices for Social Anthropology". American Anthropologist, 78 (1):5-24.

\section{Web sites Consultados:}

Scientific Electronic Library on Line - SciELO http://www.scielo.org/php/index.php CNPq www.cnpq.br 


\section{Resumo}

Este artigo busca fazer um balanço da pesquisa antropológica em saúde no Brasil e seu impacto internacional à luz das antropologias mundiais e das discussões sobre modernidade e colonialismo. Desde 1970, uma rede de antropólogos que pesquisa o tema da saúde tem se formado e consolidado, acompanhando a expansão dos programas de pós-graduação no país. Descreve-se no artigo o surgimento de grupos de pesquisa, as reuniões e as publicações, com o objetivo de caracterizar a antropologia da saúde brasileira como um programa de pesquisa distinto das antropologias norte-americanas e europeias chamadas médicas, da saúde ou da doença. Para explorar a participação de pesquisadores brasileiros no discurso global sobre saúde e, mais especificamente, no diálogo norte-sul, foram analisadas a visibilidade e a circulação das referências sobre as publicações acadêmicas na área. De uma perspectiva comparada, argumentamos que o impacto internacional das pesquisas antropológicas sobre saúde feitas no Brasil reflete tanto processos históricos e políticos desta pesquisa como a dinâmica de realização e circulação da produção acadêmica e científica no plano internacional, assim como perspectivas, interesses, ethos e valores dos pesquisadores brasileiros nesse campo do conhecimento.

Palavras-chave: Antropologia brasileira, antropologia da saúde, visibilidade acadêmica, diálogo norte-sul, desenvolvimento da pesquisa

\begin{abstract}
This article assesses the anthropological research on health in Brazil in light of discussions on "modernity/coloniality" and world anthropologies. Since the 1970s, a network of anthropologists investigating the theme of health has formed and consolidated accompanying the expansion of graduate programs in the country. We describe the emergence of research groups, meetings and publications, in order to characterize Brazilian anthropology of health as a research program that distinguishes itself from the European and North American anthropologies called "medical", "of health" or "of illness". In order to explore the participation of Brazilian researchers in the global discourse on health and, more specificially, in the North-South dialogue, the visibility and circulation of references in academic publications were examined. From a comparative perspective, we argue that the international impact of Brazilian anthropological research reflects the historical and political processes of research in Brazil, including perspectives, interests, ethos and values, as well as the dynamics of production and circulation of academic and scientific production in this field of knowledge on the international scene.
\end{abstract}

Keywords: Brazilian anthropology, anthropology of health, academic visibility, North-South dialogue, research development 